\title{
On Behavioral Response of 3D Squeezing Flow of Nanofluids in a Rotating Channel
}

\author{
Mubashir Qayyum, ${ }^{1}$ Omar Khan, ${ }^{2}$ Thabet Abdeljawad $\left(D,{ }^{3,4,5}\right.$ Naveed Imran, 6 \\ Muhammad Sohail $\mathbb{D}^{6},{ }^{6}$ and Wael Al-Kouz ${ }^{7}$ \\ ${ }^{1}$ Department of Sciences and Humanities, National University of Computer and Emerging Sciences, Lahore, Pakistan \\ ${ }^{2}$ Department of Computer Science, National University of Computer and Emerging Sciences, Peshawar, Pakistan \\ ${ }^{3}$ Department of Mathematics and General Sciences, Prince Sultan University, Riyadh, Saudi Arabia \\ ${ }^{4}$ Department of Medical Research, China Medical University, Taichung, Taiwan \\ ${ }^{5}$ Department of Computer Science and Information Engineering, Asia University, Taichung, Taiwan \\ ${ }^{6}$ Department of Applied Mathematics and Statistics, Institute of Space Technology, P.O. Box 2750, Islamabad 44000, Pakistan \\ ${ }^{7}$ Mechanical and Maintenance Engineering Department, German Jordanian University, Amman, Jordan
}

Correspondence should be addressed to Thabet Abdeljawad; tabdeljawad@psu.edu.sa

Received 6 July 2020; Revised 5 September 2020; Accepted 18 September 2020; Published 9 October 2020

Academic Editor: Alina Gavrilu

Copyright (c) 2020 Mubashir Qayyum et al. This is an open access article distributed under the Creative Commons Attribution License, which permits unrestricted use, distribution, and reproduction in any medium, provided the original work is properly cited.

\begin{abstract}
In this article, a behavioral study of three-dimensional (3D) squeezing flow of nanofluids with magnetic effect in a rotating channel has been performed. Using Navier-Stokes equations along with suitable similarity transformations, a nonlinear coupled ordinary differential system has been derived which models the 3D squeezing flow of nanofluids with lower permeable stretching porous wall where the channel is also rotating. The base fluid in the channel is considered to be water that contains different nanoparticles including silicon, copper, silver, gold, and platinum. The homotopy perturbation method (HPM) is employed for the solution of highly nonlinear coupled system. For validation purpose, system of equations is also solved through the Runge-Kutta-Fehlberg (RK45) scheme and results are compared with homotopy solutions, and excellent agreement has been found between analytical and numerical results. Also, validation has been performed by finding average residual error of the coupled system. Furthermore, the effects of various parameters such as nanoparticle volume fraction, suction parameter, characteristic parameter of the flow, magnetic parameter, rotation parameter, and different types of nanoparticles are studied graphically.
\end{abstract}

\section{Introduction}

Fluids exhibiting good thermal conductivity properties are a major requirement of many industrial applications involving heat transfer equipment. Typical examples are those of vehicular cooling systems, refrigerants, building services, and conventional industrial processing systems, such as petro-chemical, textile, paper, and food processing plants, to name a few [1-3]. To reduce costs and be energy efficient, the research and industrial community has continuously worked to develop and utilize fluids bearing high thermal conductivity. The concept of nanofluids was introduced in [4] which utilized suspended metallic nanoparticles (with a typical size of $100 \AA$ ) in conventional heat transfer fluids such as water or engine oil. Since metallic solids reflect heat conductivity of orders greater than conventional heat transfer fluids, this engineered form of fluids was received quite well by the industrial and research community. A comparison can be made on the basis of silver, $429 \mathrm{~W} /(\mathrm{m} \mathrm{K})$; water, $0.613 \mathrm{~W} /(\mathrm{m} \mathrm{K})$; and engine oil, $0.145 \mathrm{~W} /(\mathrm{m} \mathrm{K})$ at $300 \mathrm{k}$; and liquid sodium, $89.44 \mathrm{~W} /(\mathrm{m} \mathrm{K})$ at $371 \mathrm{k}$. Moreover, since the surface area to volume ratio is inversely proportional to the radius of a particle, suspended metals of nanometer scales would give better heat conductivity as compared to micrometer-sized particles. 
Since the convective heat transfer coefficient is derived from continuity, momentum, and energy equations, its behaviour is significantly dependent on the velocity and temperature profile of the nanofluid's base fluid $[1,5]$. Moreover, the heat and momentum transfer mechanisms are essentially the same and hence can be comparable on the basis of analogies. For instance, Reynold's analogy is applicable towards turbulent flows, Prandtl's analogy for laminar flows, von Korman's analogy for both laminar and turbulent flows with a buffer layer in between, and Chilton-Colburn analogy for transport independent flows [6]. The velocity is also dependent on the concentration of nanoparticles in a nanofluid such that a higher concentration may result in a flattening of the velocity profile [7]. Studies have also shown that the velocity profile is not uniform. For instance, near-wall velocity profile measurements have shown increased velocity gradient, with no slip, relative to the equivalent base fluid [8]. As such, the investigation of the velocity profile under different boundary conditions and flow models is of particular interest to the research community.

With this, a considerable volume of literature started to address the behaviour of nanofluids in context of different boundary conditions (convective [9], porous medium $[10,11])$, characterization parameters of different fluids and suspended metals $\left(\mathrm{Cu} / \mathrm{Cu}-\mathrm{TiO}_{2}[12,13]\right.$, Cu- $\mathrm{H}_{2} \mathrm{O} / \mathrm{Cu}-\mathrm{Ker}-$ osene [14]), and thermodynamic $[15,16]$ and magnetohydrodynamic [17-19] properties using analytical and/or numerical approaches. A comprehensive review of these aspects in general is presented in $[1,3,20]$.

The study of squeezing flows that is normal to two parallel plates is an important problem in the area of fluid dynamics, having applications in hydraulic machinery, electric motors, food industry, bioengineering, and automobile engines, amongst others. The mechanics of these studies in context of turbulent, laminar, and transitional flows, and different non-Newtonian fluid models (e.g., power law [21], grade 2/3 [22], and Casson [23, 24]) have proved to be a significant challenge to the research community due to the involved nonlinearities. The squeezing flow response in context of parallel plates appears in $[13,25,26]$, parallel moving plates are given in [27-29], orthogonal moving plates are discussed in [10], moving surface in [30], stretching surface in [31-33], and stretching cylinders are given in [34]. Likewise, the response to Casson flow is discussed in $[16,19,32,34]$, Hiemenz flow in [35], and bioconvection flows in $[19,36]$. The studies have also been extended to nanofluids $[1,17,25,36,37]$. In [38], Naz et al. solved analytically the problem of variable thermophysical features of the threedimensional flow of a non-Newtonian yield manifesting liquid with heat and mass transport in the presence of gyrotactic microorganisms over a nonlinear stretched surface. They utilized the boundary-layer theory to develop the governing partial differential equations. They concluded that the mounting values of the fluid parameter and magnetic parameter retard the fluid flow. Moreover [39], Ahmed et al. investigated analytically the problem of Jeffery-Hamel flow for second-grade fluid between two nonparallel walls having a source or a sink at the cusp. Soret and Dufour effects are incorporated in the energy and concentration equations. For solution purposes, the authors used the homotopy analysis method (HAM). Variations in temperature and concentration profiles for varying in grained physical parameters in the flow model are discussed graphically. Also, Nusselt number and the skin friction coefficient along with Sherwood number are extracted numerically and analytically. In [40], Khan et al. investigated viscous incompressible fluid between two nonparallel plane walls, known as Jeffery-Hamel flow, under the influence of thermal radiation. They used the similarity technique to solve for the governing equations. Moreover, the same problem is solved numerically and a comparison between the two methods is conducted that yields a great result. They presented the rates of heat and mass transfer. Furthermore, the effects of the investigated parameters on the flow and heat transfer are discussed and analyzed. Additionally [41], Khan et al. studied analytically by employing similarity technique along with Runge-Kutta and homotopy analysis algorithms the unsteady magnetohydrodynamics flow with heat generation/absorption of $\mathrm{H}_{2} \mathrm{O}$ saturated by tiny nanosized particles with various shapes over a thin slit. They found out that as the magnetic field increases, the nanofluid temperature increases and the motion decreases. In addition [42], Khan et al. investigated the flow of nanofluid over a curved Riga surface; they studied the impact of the freezing temperature and the diameter of the nanoparticles on the flow field and the heat transfer. They found out that the nanofluid velocity dropped by increasing the flow parameters $\gamma$ and $S$, and an abrupt decrement occurred at the surface of the Riga sheet. Also [43], Naz et al. investigated the entropy analysis of 3D flow of Maxwell nanofluid containing gyrotactic microorganism in the presence of homogeneous-heterogeneous reactions with improved heat conduction and mass diffusion models over a stretched surface. They found out that entropy generation increases for higher values of radiation parameter and Brinkman number, whereas the Bejan number is reduced for the higher values of radiation and magnetic parameters.

From a numerical perspective, the various behaviours are explained on the basis of solutions over discrete points distributed throughout the problem domain. Solutions for remaining points are obtained by means of interpolation. For reasons of performance and accuracy, these points appear amidst regular geometries. In context of simpler domains, reduced number of dimensions is sufficient for such studies. However, by considering richer intricacies of involved physics, the simplified problem domain is compromised, giving failed predictions. In such situations, studies on the basis of 3D domain models, even for simpler geometry configurations, are imperative. The common approach in terms of nanofluids is the fourth-order Runge-Kutta family of integration methods [44, 45]. The same is also true from an analytical perspective that takes into account simplified assumptions. The usual approach for boundary value problems is the usage of perturbation 
techniques. However, due to assumptions of small or large parameters, this is not sufficient. In this regard, a seminal work that combined these perturbation techniques with homotopy was proposed as the homotopy perturbation method (HPM) in [46-49]. Since its introduction, the method has been applied to different nonlinear equations [50-56]. Specifically, in the case of nanofluids, the method has been applied in [57-60]. Other approximation techniques that have been used for the case of fluid dynamics include the homotopy analysis method (HAM) [61] and optimal homotopy asymptotic method (OHAM) [62].

In this article, we provide a comprehensive description of the three-dimensional squeezing flow of nanofluids, considering a geometry involving a rotating channel. The flow is characterised on the basis of water as base fluid and different suspended nanoparticles. The study is performed on the basis of Navier-Stokes equations using similarity transforms. Both analytical and numerical solutions are obtained using the homotopy perturbation method and Runge-Kutta-Fehlberg scheme. Furthermore, validation of results has been performed by finding the average residual error of the coupled system. After validation, we present characterization of different configurations of nanofluids using parameters such as volume fraction, suction, flow, magnetism, and rotation.

In the remaining part of the paper, Section 2 includes mathematical formulation of the problem. Section 3 presents the basic theory of numerical approach. Section 4 comprises the results and discussion. Finally, conclusion is presented in Section 5 .

\section{Mathematical Formulation}

We consider a $3 \mathrm{D}$ rotating incompressible and electrically conducting viscous nanofluid flow between two infinite horizontal plates. The lower plate is positioned at $y=0$ and is stretched with a velocity $U_{0}(t)=a x /(1-\gamma t)$ in $x$, where $a$ is the stretching rate of the lower plate, and $\gamma$ is a characteristic constant. The upper plate is at a variable distance $h(t)=\sqrt{v_{f}(1-\gamma t) / a}$. The fluid is squeezed with a velocity $v_{h}=\mathrm{d} h / \mathrm{d} t$ in negative $y$-axis. The angular velocity $\Omega$ between the fluid and channel around $y$ is $\Omega=\omega \widehat{J} /(1-\gamma t)$, where $J$ is the flux. The lower plate intakes the flow with a velocity $-V 0 /(1-\gamma t)$. A magnetic field with density $B_{0} / \sqrt{1-\gamma}$ is applied along the $y$-axis. The system is rotating along the $y$-axis (see Figure 1). These are then introduced to obtain similarity solutions by reducing the governing equations into a system of ordinary differential equations. The governing relation for continuity and momentum of nanofluid flow in the rotating frame of reference is given as follows:

$$
\nabla \cdot V=0
$$

$\rho_{\mathrm{nf}}\left[\frac{\partial V}{\partial t}+(V \cdot \nabla) V+2 \Omega \times V\right]=\nabla \cdot T+J \times B$,

where $T$ is the Cauchy stress tensor, $J$ is the magnetic flux, and $B$ is the current density. The abovementioned governing equations can also be described by the following set of Navier-Stokes equations:

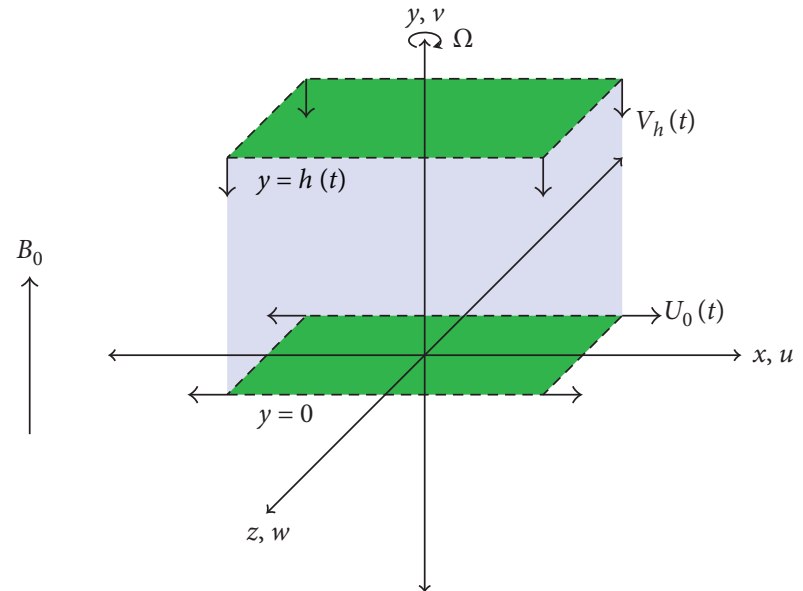

FIGURE 1: Geometry for the problem. A nanofluid is squeezed between two infinite horizontal parallel plates. The lower plate is at position $y=0$ and stretched with a velocity $U_{0}(t)$, while the upper plate is at a variable height of $h(t)$. By movement of the upper plate in negative $y$-axis, the nanofluid is squeezed at a velocity of $v_{h}(t) . \Omega$ represents the angular velocity, while $B_{0}$ is the magnetic field density applied along $y$.

$$
\begin{aligned}
& \frac{\partial u}{\partial x}+\frac{\partial v}{\partial y}=0 \\
& \frac{\partial u}{\partial t}+u \frac{\partial u}{\partial x}+v \frac{\partial u}{\partial y}+2 \frac{\omega^{2}}{1-\gamma t}=-\frac{1}{\rho_{\mathrm{nf}}} \frac{\partial p}{\partial x}+v_{\mathrm{nf}}\left[\frac{\partial^{2} u}{\partial x^{2}}\right. \\
& \left.+\frac{\partial^{2} u}{\partial y^{2}}\right]-\frac{\sigma B_{0}^{2} u}{\rho_{\mathrm{nf}}(1-\gamma t)} \\
& \frac{\partial v}{\partial t}+u \frac{\partial v}{\partial x}+v \frac{\partial v}{\partial y}=-\frac{1}{\rho_{\mathrm{nf}}} \frac{\partial p}{\partial y}+v_{\mathrm{nf}}\left[\frac{\partial^{2} v}{\partial x^{2}}+\frac{\partial^{2} v}{\partial y^{2}}\right], \\
& \frac{\partial w}{\partial t}+u \frac{\partial w}{\partial x}+v \frac{\partial w}{\partial y}-2 \frac{\omega u}{1-\gamma t}=v_{\mathrm{nf}}\left[\frac{\partial^{2} w}{\partial x^{2}}+\frac{\partial^{2} w}{\partial y^{2}}\right] \\
& -\frac{\sigma B_{0}^{2} w}{\rho_{\mathrm{nf}}(1-\gamma t)}
\end{aligned}
$$

where $\rho_{\mathrm{nf}}$ is the nanofluid density, $v_{\mathrm{nf}}=\mu_{\mathrm{nf}} / \rho_{\mathrm{nf}}$ is the nanofluid kinematic viscosity, $\sigma$ is the electrical conductivity, $B_{0}$ is the magnetic field, and $\gamma$ is a characteristic parameter representing inverse time, and $\gamma t<1$. The constants for the model are given as

$$
\begin{aligned}
& \mu_{\mathrm{nf}}=\frac{\mu_{f}}{(1-\phi)^{2.5},} \\
& \rho_{\mathrm{nf}}=(1-\phi) \rho_{f}+\phi \rho_{s},
\end{aligned}
$$

where $\mu_{f}$ is the fluid fraction viscosity, $\phi$ is the nanoparticle volume fraction, and $\rho_{f}$ and $\rho_{s}$ are the densities of the fluid and of solid fractions. The thermophysical properties of different materials are given in Table 1 for reference. The boundary conditions at $y=0$ are given as 
TABLE 1: Thermophysical property for the base fluid, along with other nanoparticles.

\begin{tabular}{lc}
\hline Material & $\rho\left(\mathrm{kg} / \mathrm{m}^{3}\right)$ \\
\hline Water, $\mathrm{H}_{2} \mathrm{O}$ & 997.1 \\
Silver, $\mathrm{Ag}$ & 10500 \\
Copper oxide, $\mathrm{CuO}$ & 6320 \\
Silicon, $\mathrm{Si}$ & 2330 \\
Gold, $\mathrm{Au}$ & 19300 \\
Aluminium oxide, $\mathrm{Al}_{2} \mathrm{O}_{3}$ & 3970 \\
Copper, $\mathrm{Cu}$ & 8933 \\
Platinum, Pt & 21450 \\
Titanium dioxide, $\mathrm{TiO}_{2}$ & 4250 \\
\hline
\end{tabular}

$$
\begin{aligned}
& u(x, y, t)=U_{0}=\frac{a x}{1-\gamma t}, \\
& v(x, y, t)=-\frac{V_{0}}{1-\gamma t}, \\
& w(x, y, t)=0 .
\end{aligned}
$$

While for $y=h(t)$, are given as

$$
\begin{aligned}
& u(x, y, t)=0, \\
& v(x, y, t)=V_{h}=\frac{\mathrm{d} h}{\mathrm{~d} t}=\frac{-\gamma}{2} \sqrt{\frac{v_{f}}{a(1-\gamma t)}}, \\
& w(x, y, t)=0
\end{aligned}
$$

where $a$ is the stretching rate of the lower plate. The governing equations subject to similarity transformation in order to give ordinary differential equations in terms of a stream function $\psi$ are given as

$$
\begin{aligned}
& \psi=\sqrt{\frac{a v_{f}}{1-\gamma t}} x f(\eta), \\
& \eta=\frac{y}{h(t)}, \\
& u=\frac{\partial \psi}{\partial y}=U_{0} f^{\prime}(\eta), \\
& v=-\frac{\partial \psi}{\partial x}=-\sqrt{\frac{a \nu_{f}}{1-\gamma t}} f(\eta), \\
& w=U_{0} g(\eta) .
\end{aligned}
$$

Substitution of these similarity transforms to the governing Navier-Stokes equations, we have

$$
\begin{aligned}
& \frac{\partial^{3} f}{\partial \eta^{3}}+\frac{\nu_{f}}{\nu_{\mathrm{nf}}}\left(f \frac{\partial^{2} f}{\partial \eta^{2}}-\left(\frac{\partial f}{\partial \eta}\right)^{2}-\beta\left(\frac{\partial f}{\partial \eta}+0.5 \eta \frac{\partial^{2} f}{\partial \eta^{2}}\right)\right. \\
& \left.-2 \Omega g-\frac{\rho_{f}}{\rho_{\mathrm{nf}}} M^{2} \frac{\partial f}{\partial \eta}\right)=\frac{(1-\gamma t)^{2} \nu_{f}}{\rho_{\mathrm{nf}} a^{2} x \nu_{\mathrm{nf}}} \frac{\partial p}{\partial x} \\
& -\frac{\partial^{2} f}{\partial \eta^{2}}+\frac{\nu_{f}}{\nu_{\mathrm{nf}}}\left(-f \frac{\partial f}{\partial \eta}+0.5 \beta\left(f+\eta \frac{\partial f}{\partial \eta}\right)\right)=\frac{1-\gamma t}{\rho_{\mathrm{nf}} a \nu_{\mathrm{nf}}} \partial p \eta \\
& \frac{\partial^{2} g}{\partial \eta^{2}}+\frac{\nu_{f}}{v_{\mathrm{nf}}}\left(f \frac{\partial g}{\partial \eta}-\frac{\partial f}{\partial \eta} g-\beta\left(g+0.5 \eta \frac{\partial g}{\partial \eta}\right)+2 \Omega \frac{\partial f}{\partial \eta}\right) \\
& -\frac{\mu_{f}}{\mu_{\mathrm{nf}}} M^{2} g=0
\end{aligned}
$$

where $\beta=\gamma / a$ is the characteristic parameter of the flow, $\Omega=w / a$ is the rotation parameter, $M^{2}=\sigma B_{0}^{2} / \rho_{f} a$ is the magnetic parameter, and prime denotes differentiation with respect to $\eta$. To squeeze the flow, we take $\beta>0$ for which the upper plates move downward with a velocity of $V_{h}<0$, whereas for $\beta<0$, the upper plate moves upwards with respect to the plane $y=0 . \beta=0$ corresponds to a steady state. To reduce the number of independent variables as well as retain the similarity solution, the above are simplified by cross-differentiation, giving us

$$
\begin{aligned}
& f^{i v}-\left(1-\phi+\frac{\phi \rho_{s}}{\rho_{f}}\right)(1-\phi)^{2.5} \times\left(f^{\prime} f^{\prime \prime}-f f^{\prime \prime \prime}+2 \Omega g^{\prime}\right. \\
& \left.\quad+0.5 \beta\left(3 f^{\prime \prime}+\eta f^{\prime \prime \prime}\right)\right)-(1-\phi)^{2.5} M^{2} f^{\prime \prime}=0, \\
& g^{\prime \prime}+\left(1-\phi+\frac{\phi \rho_{s}}{\rho_{f}}\right)(1-\phi)^{2.5} \times\left(f g^{\prime}-f^{\prime} g-\beta\left(g+0.5 \eta g^{\prime}\right)\right. \\
& \left.+2 \Omega f^{\prime}\right)-(1-\phi)^{2.5} M^{2} g=0 .
\end{aligned}
$$

Moreover, the transformed boundary conditions take the form:

$$
\begin{aligned}
f(0) & =w_{0}, \\
f^{\prime}(0) & =1, \\
g(0) & =0, \\
f(1) & =0.5 \beta, \\
f^{\prime}(1) & =0, \\
g(1) & =0,
\end{aligned}
$$

where $w_{0}=V_{0} / a h$ is the suction parameter. For this problem, the physical quantity of interest is the skin friction coefficient $C_{f}$ along the wall at the lower and upper walls, defined as 


$$
\begin{gathered}
C_{f, \text { lower }}=\frac{\mu_{\mathrm{nf}}(\partial u / \partial y)_{y=0}}{\rho_{\mathrm{nf}} U_{0}^{2}}, \\
C_{f, \text { upper }}=\frac{\mu_{\mathrm{nf}}(\partial u / \partial y)_{y=h(t)}}{\rho_{\mathrm{nf}} U_{0}^{2}} .
\end{gathered}
$$
obtain

$$
\begin{aligned}
& \bar{C}_{f, \text { lower }}=C_{f, \text { lower }} \operatorname{Re}_{x}=\frac{f^{\prime \prime}(0)}{\left(1-\phi+\phi \rho_{s} / \rho_{f}\right)(1-\phi)^{2.5}}, \\
& \bar{C}_{f, \text { upper }}=C_{f, \text { upper }} \operatorname{Re}_{x}=\frac{f^{\prime \prime}(1)}{\left(1-\phi+\phi \rho_{s} / \rho_{f}\right)(1-\phi)^{2.5}},
\end{aligned}
$$

where $\operatorname{Re}_{x}=\rho_{f} U_{0} h / \mu_{f}$ is the local Reynolds number.

\section{Basic Theory of Homotopy Perturbation Method}

The basic theory of HPM can be exhibited using the following differential equation:

$$
\begin{aligned}
L(f)+N(f)-g(r) & =0, \quad r \in \Omega, \\
B\left(f, \frac{\mathrm{d} f}{\mathrm{~d} n}\right) & =0, \quad r \in \Upsilon,
\end{aligned}
$$

where $\Upsilon$ is the boundary of the domain $\Omega$, and $f$ is unknown and $g(r)$ is a known function. $L, N, B$ are linear, nonlinear, and boundary operators, respectively. We construct a homotopy $\theta(r, p): \Omega \times[0,1] \longrightarrow R$ which satisfies

$$
\begin{array}{r}
\Psi(\theta, q)=(1-q)\left[L(\theta)-L\left(f_{0}\right)\right]+q[L(\theta)+N(\theta)-g(r)]=0, \\
r \in \Omega,
\end{array}
$$

where $q \in[0,1]$ is an embedding parameter, and $f_{0}$ is the initial guess of (13) that satisfies the boundary conditions. From (14), we have

$$
\begin{aligned}
& \Psi(\theta, 0)=L(\theta)-L\left(f_{0}\right)=0, \\
& \Psi(\theta, 1)=L(\theta)+N(\theta)-g(r)=0 .
\end{aligned}
$$

Thus, as $q$ varies from 0 to 1 , the solution $\theta(r, q)$ approaches from $f_{0}(r)$ to $\tilde{f}(r)$. To obtain an approximate solution, we expand $\theta(r, q)$ in a Taylor series about $q$ as follows:

$$
\theta(r, q)=\theta_{0}+\sum_{k=1}^{\infty} \theta_{k} q^{k} \text {. }
$$

Setting $q=1$, the approximate solution of (13) would be

$$
\widetilde{U}=\lim _{q \longrightarrow 1} \theta(r, q)=\sum_{k=1}^{\infty} \theta_{k} .
$$

Substituting equation (17) in equation (13) will give

$$
R(x)=L[\tilde{U}(x)]+N[\tilde{U}(x)]-g(x) .
$$

If $R$ is approaching zero, $\widetilde{U}$ will then approach towards the exact solution.

\section{Results and Discussion}

In this article, an unsteady three-dimensional squeezing flow of electrically conducting nanofluid between two infinite horizontal planes in a rotating channel is considered. The composition of the nanofluid is made on the basis of different nanoparticles, including Silicon ( $\mathrm{Si})$, Copper $(\mathrm{Cu})$, Silver (Ag), Gold ( $\mathrm{Au}$ ), and Platinum ( $\mathrm{Pt})$. These nanofluids with silicon composition are used for observing the effect of various parameters on the velocity profile. These parameters include the nanoparticle volume fraction $\phi$, suction parameter $w_{0}$, characteristic parameter of the flow $\beta$, rotation parameter $\Omega$, and magnetic parameter $M$. The formulated boundary value system described in Section 2 for these parameters is solved using HPM, which is then compared with numerical solutions obtained using the Runge-Kutta-Fehlberg method for validation purposes. A graphical representation for this validation is given in Figure 2, showing good agreement.

A detailed analysis of this validation is performed through residual errors, for $\phi=0.9, w_{0}=0.5, \Omega=1, \beta=1$, and $M=1$ in Tables 2 and 3 for both the HPM and RK45 methods individually. Validation with a variation of $\beta=2$ is given in Tables 4 and 5 . In both cases, the results from HPMbased solution are consistent and in good agreement with the numerical results. A comparative analysis on the basis of $\beta=(1,2)$ using both HPM and RK45 is given in Table 6 . The effect of the skin friction coefficient at both lower and upper walls is also given in Table 7 .

After validation of the solutions, the behaviour response of nanofluids against various parameters is investigated. In all these investigations, $0<\eta<0.5$ corresponds to the lower half, while $0.5<\eta<1$ represents the upper half of the channel.

The effect of nanoparticle volume fraction $\phi$ on normal, axial, and transverse velocity components is given in Figure 3. Here, the static parameters are $w_{0}=0.5, \beta=1$, $\Omega=1$, and $M=0.5$, while the variational parameter $\phi \varepsilon[0,1]$. The general observation is that $\phi$ increases with respect to normal velocity. The axial velocity profile increases with an increase in the nanoparticle volume fraction in the lower half of the channel, while it decreases in the upper half. The transverse velocity decreases in the vicinity of lower surface, $(0<\eta<0.25)$, when the nanoparticle volume fraction increases. But other than that, an opposite trend has been observed in the rest of the channel $(0.25<\eta<1)$. These behaviours are justified because viscosity increases by increasing the nanomaterial volume fraction; as a result, the enhanced frictional force leads to the flow resistance.

The response of suction parameter $\left(w_{0}\right)$ on the velocity profile is given in Figure 4, where it can be observed that the observable range of $w_{0}$ is at a maximum in the lower channel. The overall trend is similar to an exponential increase in this region. However, $w_{0}$ gets confined rapidly around the midpoint as $\eta$ and $w_{0}$ approach 1 . In the case of the axial velocity, it stands at maximum close to the lower wall at $\eta=0$ and at the midpoint close to the upper wall at $\eta=1$. In other cases, it decreases significantly as $w_{0}$ 


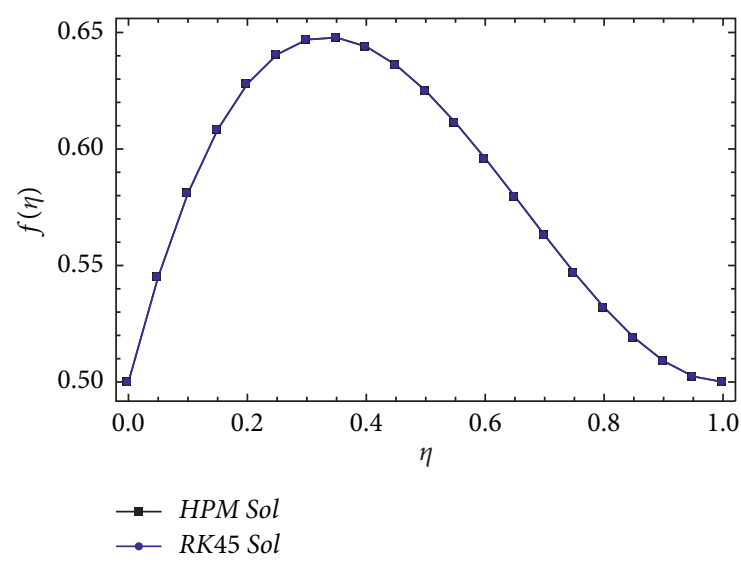

(a)

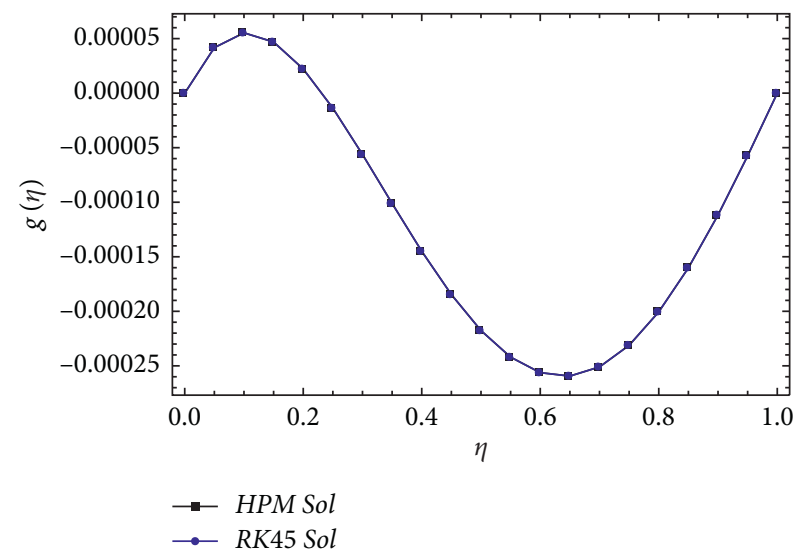

(b)

Figure 2: Comparison of analytical and numerical solutions. (a) Comparison of $f(\eta)$. (b) Comparison of $g(\eta)$.

TABLE 2: Homotopy-based solution along with residual errors when $\phi=0.9, w_{0}=0.5, \Omega=1, \beta=1$, and $M=1$.

\begin{tabular}{lccccc}
\hline$\eta$ & $f_{\text {HPM }}$ & $g_{\text {HPM }}$ & Abs error equation $(1)$ & Abs error equation $(2)$ & Average Abs error \\
\hline 0. & 0.5 & 0 & $8.306 \times 10^{-8}$ & $2.504 \times 10^{-9}$ & $4.278 \times 10^{-8}$ \\
0.05 & 0.545121 & 0.0000417402 & $4.570 \times 10^{-8}$ & $2.524 \times 10^{-9}$ & $1.525 \times 10^{-9}$ \\
0.10 & 0.580987 & 0.0000553098 & $1.937 \times 10^{-8}$ & $4.431 \times 10^{-11}$ & $1.045 \times 10^{-8}$ \\
0.15 & 0.60835 & 0.0000468996 & $1.493 \times 10^{-9}$ & $1.509 \times 10^{-9}$ & $7.686 \times 10^{-10}$ \\
0.20 & 0.627961 & 0.0000221747 & $9.986 \times 10^{-9}$ & $2.844 \times 10^{-9}$ & $5.748 \times 10^{-9}$ \\
0.25 & 0.640574 & -0.0000137254 & $1.662 \times 10^{-8}$ & $3.778 \times 10^{-9}$ & $9.735 \times 10^{-9}$ \\
0.30 & 0.646938 & -0.0000561855 & $1.962 \times 10^{-8}$ & $4.223 \times 10^{-9}$ & $1.170 \times 10^{-8}$ \\
0.35 & 0.647805 & -0.000101115 & $1.990 \times 10^{-8}$ & $4.170 \times 10^{-9}$ & $1.206 \times 10^{-8}$ \\
0.40 & 0.643925 & -0.000144946 & $1.817 \times 10^{-8}$ & $3.672 \times 10^{-9}$ & $1.117 \times 10^{-8}$ \\
0.45 & 0.636048 & -0.000184635 & $1.500 \times 10^{-8}$ & $2.828 \times 10^{-9}$ & $9.341 \times 10^{-9}$ \\
0.50 & 0.624925 & -0.000217661 & $1.088 \times 10^{-8}$ & $6.138 \times 10^{-10}$ & $6.859 \times 10^{-9}$ \\
0.55 & 0.611304 & -0.000242025 & $6.239 \times 10^{-9}$ & $4.837 \times 10^{-10}$ & $4.001 \times 10^{-9}$ \\
0.60 & 0.595936 & -0.00025625 & $1.448 \times 10^{-9}$ & $1.408 \times 10^{-9}$ & $1.031 \times 10^{-9}$ \\
0.65 & 0.57957 & -0.000259381 & $3.111 \times 10^{-9}$ & $2.061 \times 10^{-9}$ & $1.797 \times 10^{-9}$ \\
0.70 & 0.562955 & -0.000250985 & $7.086 \times 10^{-9}$ & $2.375 \times 10^{-9}$ & $4.247 \times 10^{-9}$ \\
0.75 & 0.546841 & -0.000231151 & $1.014 \times 10^{-8}$ & $2.313 \times 10^{-9}$ & $6.105 \times 10^{-9}$ \\
0.80 & 0.531976 & -0.000200489 & $1.199 \times 10^{-8}$ & $1.873 \times 10^{-9}$ & $7.187 \times 10^{-9}$ \\
0.85 & 0.519111 & -0.000160129 & $1.239 \times 10^{-8}$ & $1.083 \times 10^{-9}$ & $7.352 \times 10^{-9}$ \\
0.90 & 0.508993 & -0.000111724 & $1.114 \times 10^{-8}$ & $1.180 \times 10^{-19}$ & $6.508 \times 10^{-9}$ \\
0.95 & 0.502373 & -0.0000574492 & $8.143 \times 10^{-9}$ & & $4.613 \times 10^{-9}$ \\
1. & 0.5 & $2.7 \times 10^{-21}$ & $3.371 \times 10^{-9}$ & & $1.685 \times 10^{-9}$ \\
\hline
\end{tabular}

increases. This results in a reverse flow due to discharge of a large amount of fluid particles in the vicinity of the lower wall, while on the upper wall, it becomes much more noticeable. In the case of the traverse component of velocity profile, there is almost no change as the maximum range of the velocity profile stands at 0.002 . In this case, the velocity is nonexistent at both walls. In all these cases, the static parameters are $\phi=0.9, \beta=1, \Omega=1$, and $M=0.5$, while the variable parameter $w_{0} \varepsilon[0,1]$.

The effect of magnetic parameter $M$ on the velocity profile is shown in Figure 5. Here, the static parameters are $\phi=0.2, w_{0}=0.5, \beta=1$, and $\Omega=1$, while the variable parameters are $M \varepsilon[0,0.6]$. In these cases, the normal velocity presents a tailed parabolic behaviour, as $M$ is increased, where in the region in vicinity of lower plate shows an increased flow, but a decreased flow a little before the channel midpoint. The axial velocity component also has dual behaviour, where it decreases with an increase in $M$ in the lower channel, while showing an increasing behaviour in the upper channel. In the transverse component, the velocity component is zero at both the upper and lower walls, whereas at the center of the channel, the maximum range for different $M$ stands at 0.04. But in general, a positive transverse velocity component is only observable if $M>0.5$. The reason behind these behaviours is that application of magnetic field to an electrically conducting fluid gives rise to a resistive type force called the Lorentz force. This force has the tendency to slow down the motion of the fluid.

The effect of characteristic parameter $\beta$ on the velocity profile, while the static parameters are $\phi=0.9, w_{0}=0.5$, $\Omega=1$, and $M=0.5$ and while $\beta$ varies in the interval $[-2.5,2.5]$, is presented in Figures 6 and 7. Positive values of $\beta$ representing movement of the upper plate towards the lower plate, all three velocity components, demonstrate an 
TABLE 3: RK45 solution along with residual errors when $\phi=0.9, w_{0}=0.5, \Omega=1, \beta=1$, and $M=1$.

\begin{tabular}{lccccc}
\hline$\eta$ & $f_{R K 45}$ & $g_{R K 45}$ & Error equation $(1)$ & Error equation $(2)$ & Average Abs error \\
\hline 0. & 0.5 & 0 & $4.353 \times 10^{-4}$ & $1.868 \times 10^{-8}$ & $2.176 \times 10^{-4}$ \\
0.05 & 0.545121 & 0.0000417403 & $2.140 \times 10^{-4}$ & $5.805 \times 10^{-9}$ & $1.070 \times 10^{-4}$ \\
0.10 & 0.580987 & 0.0000553099 & $9.222 \times 10^{-5}$ & $8.619 \times 10^{-10}$ & $4.611 \times 10^{-5}$ \\
0.15 & 0.60835 & 0.0000468997 & $3.185 \times 10^{-5}$ & $5.766 \times 10^{-10}$ & $7.509 \times 10^{-10}$ \\
0.20 & 0.627961 & 0.0000221748 & $6.477 \times 10^{-6}$ & $6.336 \times 10^{-10}$ & $3.239 \times 10^{-6}$ \\
0.25 & 0.640574 & -0.0000137252 & $1.205 \times 10^{-6}$ & $5.402 \times 10^{-10}$ & $6.032 \times 10^{-7}$ \\
0.30 & 0.646938 & -0.0000561853 & $1.634 \times 10^{-6}$ & $5.064 \times 10^{-10}$ & $8.173 \times 10^{-7}$ \\
0.35 & 0.647805 & -0.000101115 & $3.276 \times 10^{-7}$ & $4.915 \times 10^{-10}$ & $1.640 \times 10^{-7}$ \\
0.40 & 0.643925 & -0.000144946 & $4.547 \times 10^{-7}$ & $4.672 \times 10^{-10}$ & $2.276 \times 10^{-7}$ \\
0.45 & 0.636048 & -0.000184635 & $3.610 \times 10^{-7}$ & $4.345 \times 10^{-10}$ & $1.807 \times 10^{-7}$ \\
0.50 & 0.624925 & -0.000217661 & $1.067 \times 10^{-7}$ & $3.088 \times 10^{-10}$ & $5.361 \times 10^{-8}$ \\
0.55 & 0.611304 & -0.000242025 & $3.463 \times 10^{-7}$ & $3.966 \times 10^{-10}$ & $1.733 \times 10^{-7}$ \\
0.60 & 0.595936 & -0.000256249 & $1.062 \times 10^{-7}$ & $3.857 \times 10^{-10}$ & $5.332 \times 10^{-8}$ \\
0.65 & 0.57957 & -0.000259381 & $3.624 \times 10^{-7}$ & $3.646 \times 10^{-10}$ & $1.814 \times 10^{-7}$ \\
0.70 & 0.562955 & -0.000250985 & $4.570 \times 10^{-7}$ & $3.611 \times 10^{-10}$ & $2.287 \times 10^{-7}$ \\
0.75 & 0.546841 & -0.000231151 & $3.247 \times 10^{-7}$ & $4.189 \times 10^{-10}$ & $1.625 \times 10^{-7}$ \\
0.80 & 0.531976 & -0.000200489 & $1.631 \times 10^{-6}$ & $5.075 \times 10^{-10}$ & $8.160 \times 10^{-7}$ \\
0.85 & 0.519111 & -0.000160129 & $1.203 \times 10^{-6}$ & $3.023 \times 10^{-10}$ & $3.243 \times 10^{-6}$ \\
0.90 & 0.508993 & -0.000111724 & $6.485 \times 10^{-6}$ & $1.233 \times 10^{-9}$ & $1.594 \times 10^{-5}$ \\
0.95 & 0.502373 & -0.0000574492 & $3.188 \times 10^{-5}$ & & $4.616 \times 10^{-5}$ \\
1. & 0.5 & $2.9 \times 10^{-12}$ & $9.233 \times 10^{-5}$ & &
\end{tabular}

TABLE 4: Homotopy-based solution along with residual errors when $\phi=0.9, w_{0}=0.5, \Omega=1, \beta=2$, and $M=1$.

\begin{tabular}{|c|c|c|c|c|c|}
\hline$\eta$ & $f_{\text {HPM }}$ & $g_{\mathrm{HPM}}$ & Error equation (1) & Error equation (2) & Average Abs error \\
\hline 0. & 0.5 & 0 & $4.793 \times 10^{-8}$ & $1.700 \times 10^{-8}$ & $3.247 \times 10^{-8}$ \\
\hline 0.05 & 0.548747 & 0.00021484 & $4.773 \times 10^{-8}$ & $1.224 \times 10^{-8}$ & $2.998 \times 10^{-8}$ \\
\hline 0.10 & 0.594991 & 0.000396569 & $4.876 \times 10^{-8}$ & $5.672 \times 10^{-9}$ & $2.721 \times 10^{-8}$ \\
\hline 0.15 & 0.638731 & 0.000546947 & $4.997 \times 10^{-8}$ & $1.859 \times 10^{-9}$ & $2.591 \times 10^{-8}$ \\
\hline 0.20 & 0.67997 & 0.000667732 & $5.049 \times 10^{-8}$ & $9.659 \times 10^{-9}$ & $3.007 \times 10^{-8}$ \\
\hline 0.25 & 0.718709 & 0.000760677 & $4.966 \times 10^{-8}$ & $1.716 \times 10^{-8}$ & $3.341 \times 10^{-8}$ \\
\hline 0.30 & 0.754949 & 0.000827534 & $4.701 \times 10^{-8}$ & $2.394 \times 10^{-8}$ & $3.548 \times 10^{-8}$ \\
\hline 0.35 & 0.78869 & 0.00087005 & $4.224 \times 10^{-8}$ & $2.967 \times 10^{-8}$ & $3.595 \times 10^{-8}$ \\
\hline 0.40 & 0.819934 & 0.000889971 & $3.521 \times 10^{-8}$ & $3.413 \times 10^{-8}$ & $3.467 \times 10^{-8}$ \\
\hline 0.45 & 0.84868 & 0.000889042 & $2.596 \times 10^{-8}$ & $3.719 \times 10^{-8}$ & $3.157 \times 10^{-8}$ \\
\hline 0.50 & 0.874928 & 0.000869003 & $1.467 \times 10^{-8}$ & $3.882 \times 10^{-8}$ & $2.674 \times 10^{-8}$ \\
\hline 0.55 & 0.89868 & 0.000831597 & $1.677 \times 10^{-9}$ & $3.905 \times 10^{-8}$ & $2.036 \times 10^{-8}$ \\
\hline 0.60 & 0.919934 & 0.00077856 & $1.255 \times 10^{-8}$ & $3.795 \times 10^{-8}$ & $2.525 \times 10^{-8}$ \\
\hline 0.65 & 0.938691 & 0.000711631 & $2.741 \times 10^{-8}$ & $3.565 \times 10^{-8}$ & $3.153 \times 10^{-8}$ \\
\hline 0.70 & 0.95495 & 0.000632547 & $4.219 \times 10^{-8}$ & $3.233 \times 10^{-8}$ & $3.726 \times 10^{-8}$ \\
\hline 0.75 & 0.96871 & 0.000543044 & $5.605 \times 10^{-8}$ & $2.815 \times 10^{-8}$ & $4.210 \times 10^{-8}$ \\
\hline 0.80 & 0.979971 & 0.000444857 & $6.805 \times 10^{-8}$ & $2.329 \times 10^{-8}$ & $4.567 \times 10^{-8}$ \\
\hline 0.85 & 0.988732 & 0.000339724 & $7.716 \times 10^{-8}$ & $1.793 \times 10^{-8}$ & $4.755 \times 10^{-8}$ \\
\hline 0.90 & 0.994991 & 0.000229378 & $8.228 \times 10^{-8}$ & $1.221 \times 10^{-8}$ & $4.724 \times 10^{-8}$ \\
\hline 0.95 & 0.998747 & 0.000115558 & $8.220 \times 10^{-8}$ & $6.221 \times 10^{-9}$ & $4.421 \times 10^{-8}$ \\
\hline 1. & 1. & $1.1 \times 10^{-18}$ & $7.567 \times 10^{-8}$ & $3.715 \times 10^{-20}$ & $3.783 \times 10^{-8}$ \\
\hline
\end{tabular}

increase (see Figure 6). On the contrary, the inverse movement is represented by the negative $\beta$ values; all velocity components record a decrease as $\beta$ is decreased (see Figure 7).

Effect of rotational parameter $\Omega$ on the velocity profile is depicted in Figure 8 . For $\Omega$, the normal velocity decreases as $\Omega$ is increased. The axial velocity shows a dual behaviour. In the lower part of the channel, there is a small decrease in the velocity as $\Omega$ is increased, whereas in the upper part of the channel, there is a small increase as $\Omega$ is increased. An inverse dual behaviour to the axial component is reflected in the transverse component. Here, there is small increase in velocity as $\Omega$ is increased in the lower quarter of the channel, whereas in the remaining three quarters, there is a major reversal of velocity as $\Omega$ is increased. Here, the static parameters are $\phi=0.2, w_{0}=0.5, \beta=1$, and $M=0.5$, while the variational parameter is $\Omega=[3,12]$. The transverse velocity component shows a similar behaviour in the case of increased nanoparticle volume fraction $\phi$ and the rotation parameter $\Omega$. Magnitudes of these velocities are found to decease within the rotating channel with augmentation. One of the forces encountered in fluid flow with a rotating 
TABLE 5: RK45 solution along with residual errors when $\phi=0.9, w_{0}=0.5, \Omega=1, \beta=2$, and $M=1$.

\begin{tabular}{lccccc}
\hline$\eta$ & $f_{R K 45}$ & $g_{R K 45}$ & Error equation $(1)$ & Error equation $(2)$ & Average Abs error \\
\hline 0. & 0.5 & 0 & $1.501 \times 10^{-6}$ & $5.984 \times 10^{-10}$ & $7.510 \times 10^{-7}$ \\
0.05 & 0.548747 & 0.00021484 & $3.007 \times 10^{-7}$ & $2.663 \times 10^{-10}$ & $7.585 \times 10^{-11}$ \\
0.10 & 0.594991 & 0.00039657 & $1.054 \times 10^{-7}$ & $4.817 \times 10^{-12}$ & $5.276 \times 10^{-8}$ \\
0.15 & 0.638731 & 0.000546948 & $1.480 \times 10^{-7}$ & $2.357 \times 10^{-11}$ & $7.401 \times 10^{-8}$ \\
0.20 & 0.67997 & 0.000667734 & $7.506 \times 10^{-8}$ & $1.921 \times 10^{-11}$ & $3.754 \times 10^{-8}$ \\
0.25 & 0.718709 & 0.000760679 & $6.392 \times 10^{-9}$ & $1.337 \times 10^{-11}$ & $3.205 \times 10^{-9}$ \\
0.30 & 0.754949 & 0.000827536 & $2.043 \times 10^{-8}$ & $1.253 \times 10^{-11}$ & $1.022 \times 10^{-8}$ \\
0.35 & 0.78869 & 0.000870053 & $1.291 \times 10^{-8}$ & $1.454 \times 10^{-11}$ & $6.464 \times 10^{-9}$ \\
0.40 & 0.819934 & 0.000889974 & $4.944 \times 10^{-9}$ & $1.537 \times 10^{-11}$ & $2.479 \times 10^{-9}$ \\
0.45 & 0.84868 & 0.000889045 & $1.240 \times 10^{-8}$ & $1.366 \times 10^{-11}$ & $6.208 \times 10^{-9}$ \\
0.50 & 0.874928 & 0.000869007 & $3.028 \times 10^{-9}$ & $1.152 \times 10^{-11}$ & $1.521 \times 10^{-9}$ \\
0.55 & 0.89868 & 0.0008316 & $1.297 \times 10^{-8}$ & $1.533 \times 10^{-11}$ & $6.493 \times 10^{-9}$ \\
0.60 & 0.919934 & 0.000778563 & $1.521 \times 10^{-8}$ & $1.557 \times 10^{-11}$ & $7.613 \times 10^{-9}$ \\
0.65 & 0.938691 & 0.000711634 & $1.173 \times 10^{-8}$ & $5.230 \times 10^{-12}$ & $5.876 \times 10^{-9}$ \\
0.70 & 0.95495 & 0.00063255 & $5.443 \times 10^{-8}$ & $8.678 \times 10^{-12}$ & $2.722 \times 10^{-8}$ \\
0.75 & 0.96871 & 0.000543046 & $3.789 \times 10^{-8}$ & $3.236 \times 10^{-11}$ & $1.895 \times 10^{-8}$ \\
0.80 & 0.979971 & 0.00044486 & $2.157 \times 10^{-7}$ & $3.052 \times 10^{-10}$ & $5.186 \times 10^{-7}$ \\
0.85 & 0.988732 & 0.000339725 & $1.037 \times 10^{-6}$ & $1.212 \times 10^{-9}$ & $1.484 \times 10^{-6}$ \\
0.90 & 0.994991 & 0.00022938 & $2.969 \times 10^{-6}$ & $3.545 \times 10^{-9}$ & $3.417 \times 10^{-6}$ \\
0.95 & 0.998747 & 0.000115559 & $6.834 \times 10^{-6}$ & & $6.906 \times 10^{-6}$ \\
1. & 1. & $1.2 \times 10^{-14}$ & $1.380 \times 10^{-5}$ & &
\end{tabular}

TABLE 6: Similarity between HPM and RK45 solutions when $\phi=0.9, w_{0}=0.5, \Omega=1$, and $M=1$.

\begin{tabular}{|c|c|c|c|c|c|c|}
\hline \multicolumn{4}{|c|}{$\beta=1$} & \multicolumn{3}{|c|}{$\beta=2$} \\
\hline$\eta$ & $\left|f_{\mathrm{HPM}}-f_{R K 45}\right|$ & $\left|g_{\mathrm{HPM}}-g_{R K 45}\right|$ & System similarity & $\left|f_{\mathrm{HPM}}-f_{R K 45}\right|$ & $\left|g_{\mathrm{HPM}}-g_{R K 45}\right|$ & System similarity \\
\hline 0. & 0 & 0 & 0 & 0 & 0 & 0 \\
\hline 0.05 & $2.412 \times 10^{-10}$ & $1.637 \times 10^{-11}$ & $1.288 \times 10^{-10}$ & $3.539 \times 10^{-11}$ & $4.298 \times 10^{-10}$ & $7.606 \times 10^{-21}$ \\
\hline 0.10 & $4.490 \times 10^{-10}$ & $5.474 \times 10^{-11}$ & $2.519 \times 10^{-10}$ & $5.962 \times 10^{-11}$ & $8.905 \times 10^{-10}$ & $2.654 \times 10^{-20}$ \\
\hline 0.15 & $1.175 \times 10^{-9}$ & $9.915 \times 10^{-11}$ & $6.374 \times 10^{-10}$ & $7.397 \times 10^{-11}$ & $1.365 \times 10^{-9}$ & $5.050 \times 10^{-20}$ \\
\hline 0.20 & $1.683 \times 10^{-9}$ & $1.420 \times 10^{-10}$ & $9.128 \times 10^{-10}$ & $7.972 \times 10^{-11}$ & $1.835 \times 10^{-9}$ & $7.316 \times 10^{-20}$ \\
\hline 0.25 & $1.953 \times 10^{-9}$ & $1.790 \times 10^{-10}$ & $1.066 \times 10^{-9}$ & $7.861 \times 10^{-11}$ & $2.281 \times 10^{-9}$ & $8.968 \times 10^{-20}$ \\
\hline 0.30 & $2.024 \times 10^{-9}$ & $2.074 \times 10^{-10}$ & $1.116 \times 10^{-9}$ & $7.257 \times 10^{-11}$ & $2.684 \times 10^{-9}$ & $9.741 \times 10^{-20}$ \\
\hline 0.35 & $1.936 \times 10^{-9}$ & $2.250 \times 10^{-10}$ & $1.080 \times 10^{-9}$ & $6.328 \times 10^{-11}$ & $3.028 \times 10^{-9}$ & $9.583 \times 10^{-20}$ \\
\hline 0.40 & $1.720 \times 10^{-9}$ & $2.310 \times 10^{-10}$ & $9.757 \times 10^{-10}$ & $5.206 \times 10^{-11}$ & $3.298 \times 10^{-9}$ & $8.587 \times 10^{-20}$ \\
\hline 0.45 & $1.404 \times 10^{-9}$ & $2.257 \times 10^{-10}$ & $8.151 \times 10^{-10}$ & $3.989 \times 10^{-11}$ & $3.483 \times 10^{-9}$ & $6.948 \times 10^{-20}$ \\
\hline 0.50 & $1.019 \times 10^{-9}$ & $2.103 \times 10^{-10}$ & $6.151 \times 10^{-10}$ & $2.755 \times 10^{-11}$ & $3.575 \times 10^{-9}$ & $4.926 \times 10^{-20}$ \\
\hline 0.55 & $5.990 \times 10^{-10}$ & $1.871 \times 10^{-10}$ & $3.930 \times 10^{-10}$ & $1.572 \times 10^{-11}$ & $3.571 \times 10^{-9}$ & $2.807 \times 10^{-20}$ \\
\hline 0.60 & $1.741 \times 10^{-10}$ & $1.588 \times 10^{-10}$ & $1.664 \times 10^{-10}$ & $4.997 \times 10^{-12}$ & $3.469 \times 10^{-9}$ & $8.670 \times 10^{-21}$ \\
\hline 0.65 & $2.241 \times 10^{-10}$ & $1.282 \times 10^{-10}$ & $1.761 \times 10^{-10}$ & $4.088 \times 10^{-12}$ & $3.274 \times 10^{-9}$ & $6.693 \times 10^{-21}$ \\
\hline 0.70 & $5.655 \times 10^{-10}$ & $9.813 \times 10^{-11}$ & $3.318 \times 10^{-10}$ & $1.099 \times 10^{-11}$ & $2.989 \times 10^{-9}$ & $1.643 \times 10^{-20}$ \\
\hline 0.75 & $8.180 \times 10^{-10}$ & $7.073 \times 10^{-11}$ & $4.443 \times 10^{-10}$ & $1.492 \times 10^{-11}$ & $2.624 \times 10^{-9}$ & $1.958 \times 10^{-20}$ \\
\hline 0.80 & $9.476 \times 10^{-10}$ & $4.764 \times 10^{-11}$ & $4.976 \times 10^{-10}$ & $1.452 \times 10^{-11}$ & $2.188 \times 10^{-9}$ & $1.589 \times 10^{-20}$ \\
\hline 0.85 & $9.231 \times 10^{-10}$ & $2.953 \times 10^{-11}$ & $4.763 \times 10^{-10}$ & $8.116 \times 10^{-12}$ & $1.695 \times 10^{-9}$ & $6.881 \times 10^{-21}$ \\
\hline 0.90 & $7.216 \times 10^{-10}$ & $1.600 \times 10^{-11}$ & $3.688 \times 10^{-10}$ & $4.466 \times 10^{-12}$ & $1.157 \times 10^{-9}$ & $2.585 \times 10^{-21}$ \\
\hline 0.95 & $3.203 \times 10^{-10}$ & $5.652 \times 10^{-12}$ & $1.630 \times 10^{-10}$ & $1.623 \times 10^{-11}$ & $5.881 \times 10^{-10}$ & $4.773 \times 10^{-21}$ \\
\hline 1. & $3.622 \times 10^{-10}$ & $2.910 \times 10^{-12}$ & $1.825 \times 10^{-10}$ & $1.214 \times 10^{-13}$ & $1.263 \times 10^{-14}$ & $7.673 \times 10^{-28}$ \\
\hline
\end{tabular}

channel is the Coriolis force which acts in a direction perpendicular to the rotational axis and the velocity of the body in the rotating frame. This is due to the fact that the rotation of the channel leads to resist the flow.

The behaviour of velocity profiles against different nanofluid composition is given in Figure 9. In general, the nanofluids having greater density of nanoparticles per unit area are affecting the velocity profiles significantly, where larger densities showed a decrease in normal velocity as compared to smaller densities. For a similar volume fraction of $\phi=0.2$, Si-based nanoparticles with $\rho=2330 \mathrm{~kg} / \mathrm{m}^{3}$, i.e. the minimum most in the chosen group, reflected maximum normal velocity. In contrast, Pt having $\rho=21450 \mathrm{~kg} / \mathrm{m}^{3}$ as the highest density in the chosen group showed the minimum normal velocity. In the case of axial component, there is a dual behaviour, with high densities having a lower velocity in lower channel, and an increased velocity in the upper channel. However, the variation in velocity with 
TABLE 7: Skin friction coefficient for various values of parameters at lower and upper walls.

\begin{tabular}{|c|c|c|c|c|c|c|}
\hline$\phi$ & $w_{0}$ & $M$ & $\beta$ & $\Omega$ & $C_{f, \text { lower }}$ & $C_{f \text {,upper }}$ \\
\hline 0.9 & 0.5 & 0.5 & 1.0 & 1.0 & -0.00574602 & 0.00286874 \\
\hline 0.6 & & & & & -22.3924 & 10.7677 \\
\hline 0.3 & & & & & -7.4334 & 3.28618 \\
\hline 0.0 & & & & & -4.48572 & 1.80803 \\
\hline \multirow[t]{6}{*}{0.9} & 0.0 & & & & -143.722 & -143.706 \\
\hline & 0.1 & & & & -229.876 & -57.5714 \\
\hline & 0.2 & & & & -316.041 & 28.5537 \\
\hline & 0.3 & & & & -402.217 & 114.67 \\
\hline & 0.6 & & & & -660.81 & 372.963 \\
\hline & 0.9 & & & & -919.501 & 631.173 \\
\hline \multirow[t]{5}{*}{0.2} & 0.5 & 0.0 & & & -5.96224 & 2.56784 \\
\hline & & 1.0 & & & -6.06434 & 2.54659 \\
\hline & & 2.0 & & & -6.36118 & 2.48844 \\
\hline & & 4.0 & & & -7.40657 & 2.33973 \\
\hline & & 6.0 & & & -8.64416 & 2.39013 \\
\hline \multirow[t]{8}{*}{0.9} & & 0.5 & & & -574.602 & 286.874 \\
\hline & & & 1.5 & & -359.247 & 71.5441 \\
\hline & & & 2.0 & & -143.847 & -143.831 \\
\hline & & & 2.5 & & 71.5972 & -359.25 \\
\hline & & & -1.0 & & -1435.58 & 1147.75 \\
\hline & & & -1.5 & & -1650.71 & 1362.85 \\
\hline & & & -2.0 & & -1865.79 & 1577.92 \\
\hline & & & -2.5 & & -2080.84 & 1792.93 \\
\hline \multirow[t]{7}{*}{0.2} & & & 1.0 & 0.5 & -5.9823 & 2.56287 \\
\hline & & & & 1.0 & -5.98791 & 2.56244 \\
\hline & & & & 3.0 & -6.04779 & 2.55783 \\
\hline & & & & 5.0 & -6.16755 & 2.54862 \\
\hline & & & & 7.0 & -6.3472 & 2.5348 \\
\hline & & & & 9.0 & -6.58672 & 2.51637 \\
\hline & & & & 12.0 & -7.05828 & 2.4801 \\
\hline
\end{tabular}

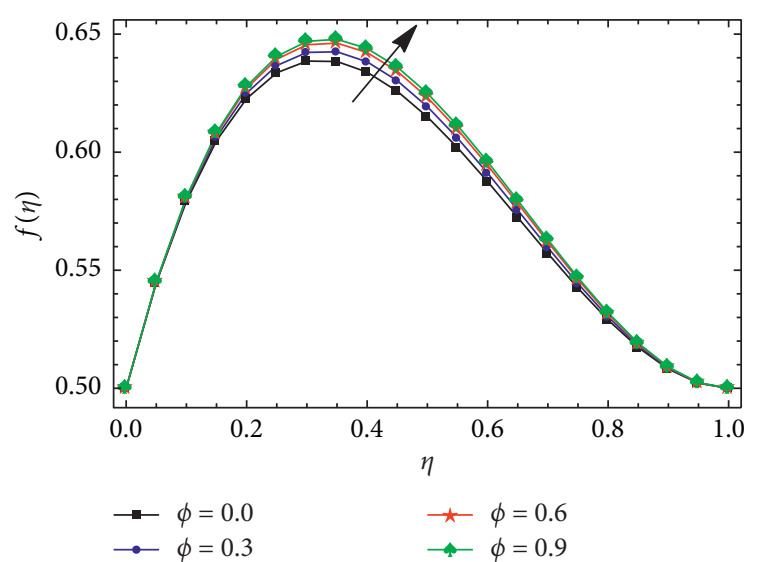

(a)

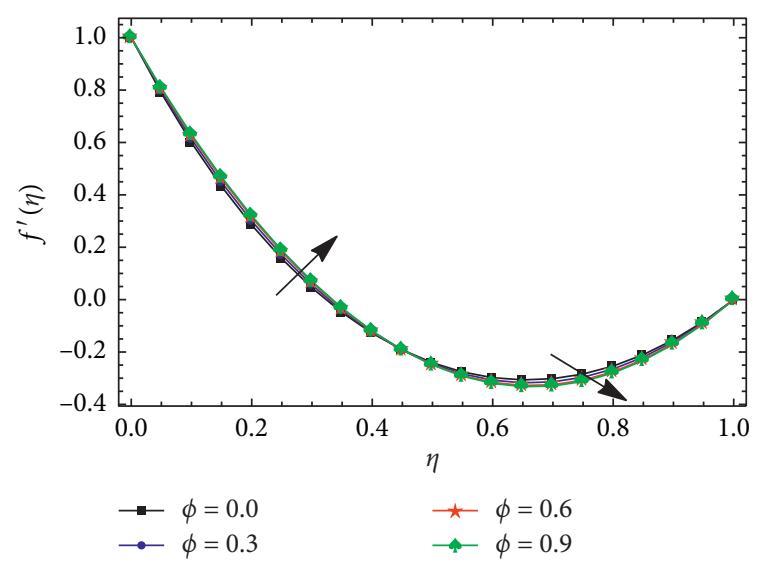

(b)

FIgUre 3: Continued. 


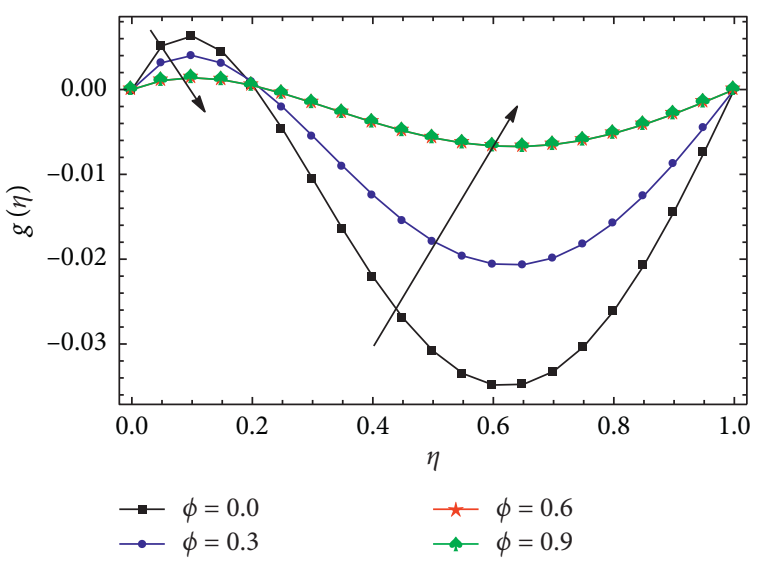

(c)

Figure 3: Effect of nanoparticle volume fraction $\phi$ on the velocity profile when $w_{0}=0.5, \beta=1, \Omega=1$, and $M=0.5$. (a) Normal component of velocity. (b) Axial component of velocity. (c) Transverse component of velocity.

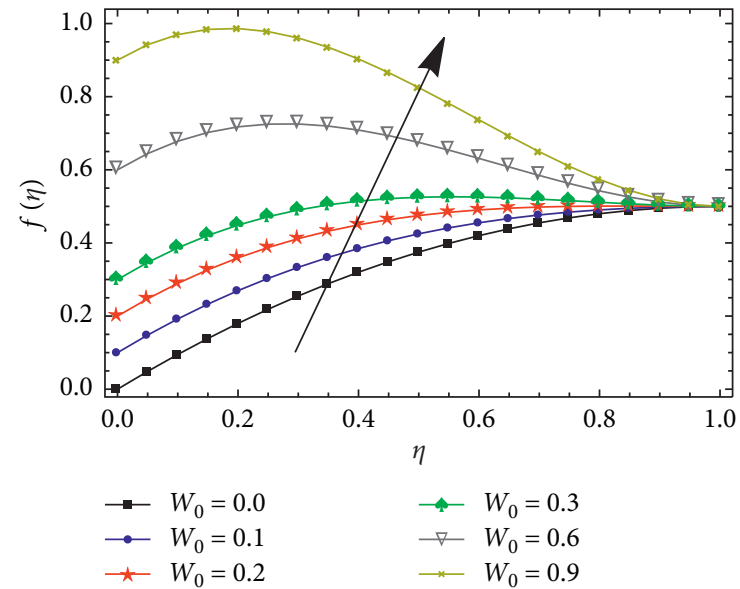

(a)

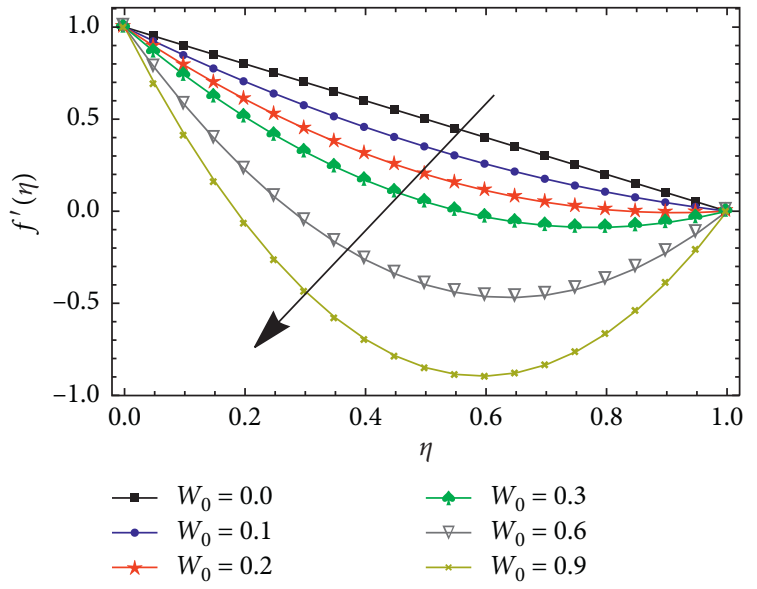

(b)

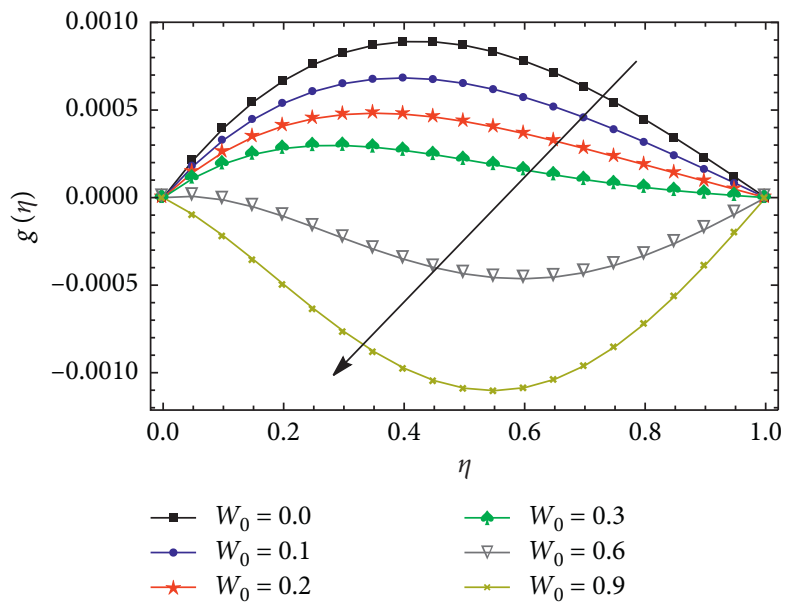

(c)

FIGURE 4: Effect of suction parameter $w_{0}$ on the velocity profile when $\phi=0.9, \beta=1, \Omega=1$, and $M=0.5$. (a) Normal component of velocity. (b) Axial component of velocity. (c) Transverse component of velocity. 

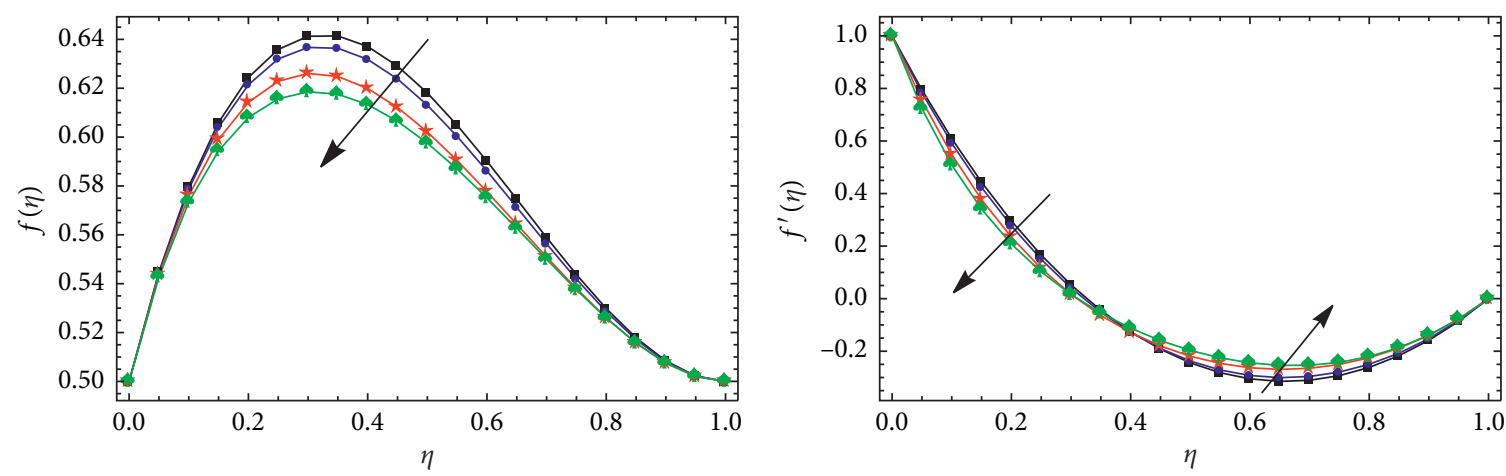

$\longrightarrow M=00$
$\because M=02$

太 $M=04$

$\rightarrow \quad M=00$

* $M=04$

(a)

(b)

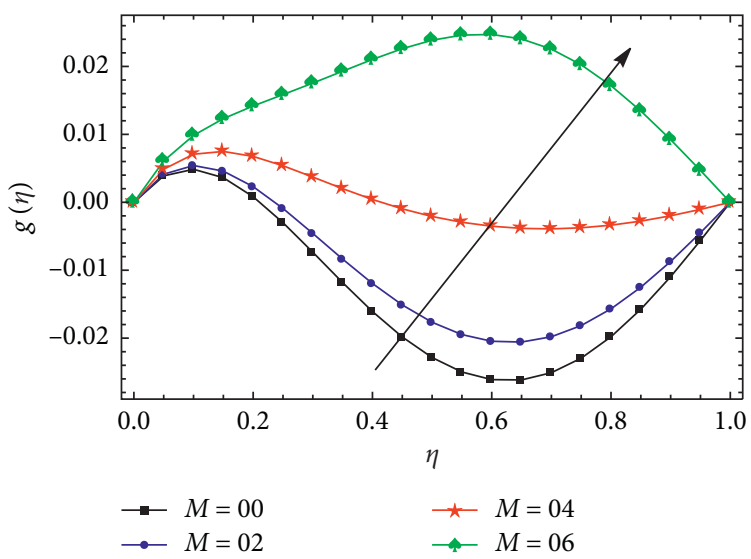

(c)

Figure 5: Effect of magnetic parameter $M$ on the velocity profile when $\phi=0.2, w_{0}=0.5, \beta=1$, and $\Omega=1$. (a) Normal component of velocity. (b) Axial component of velocity. (c) Transverse component of velocity.

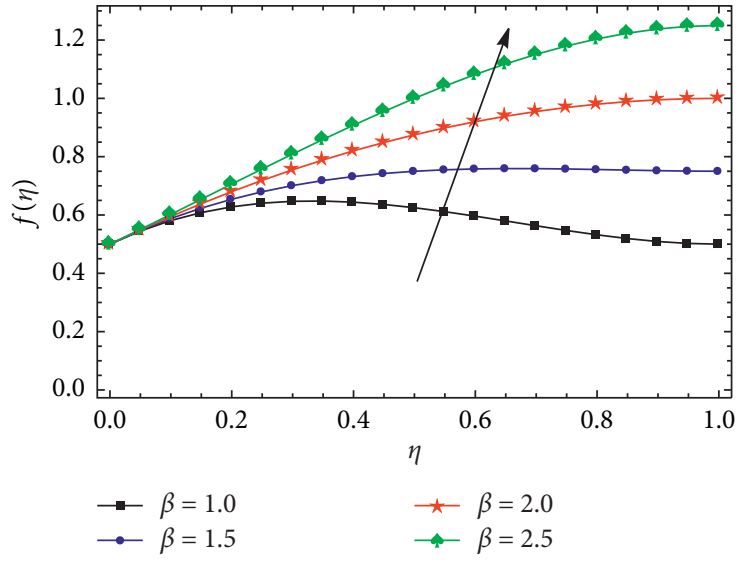

(a)

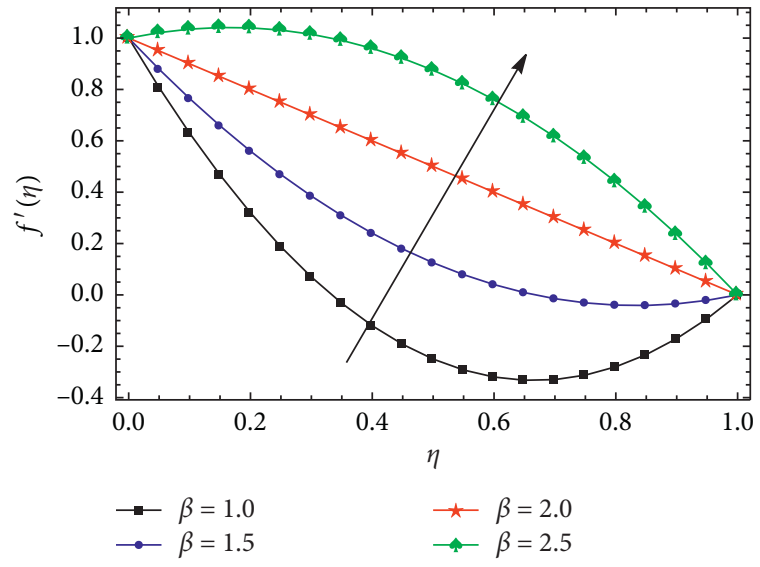

(b)

FIgURE 6: Continued. 


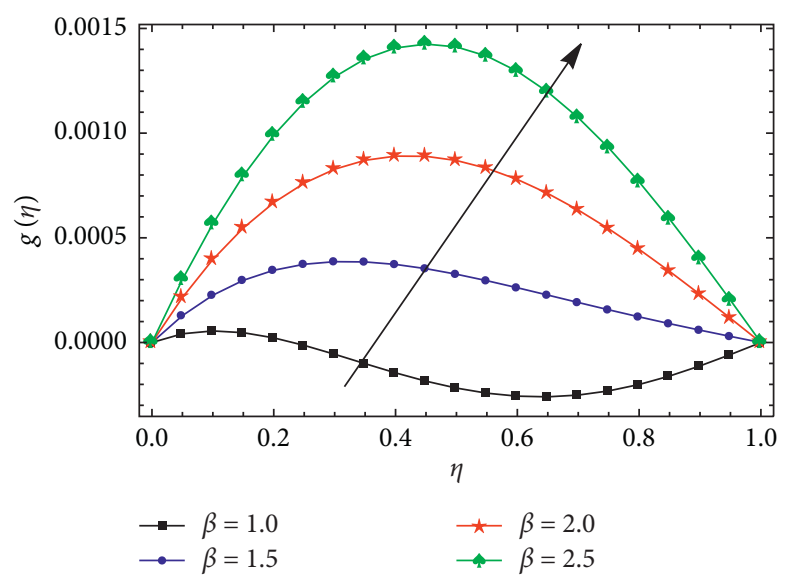

(c)

FIgURE 6: Effect of positive values of characteristic parameter $\beta$ on the velocity profile when $\phi=0.9, w_{0}=0.5, \Omega=1$, and $M=0.5$. (a) Normal component of velocity. (b) Axial component of velocity. (c) Transverse component of velocity.

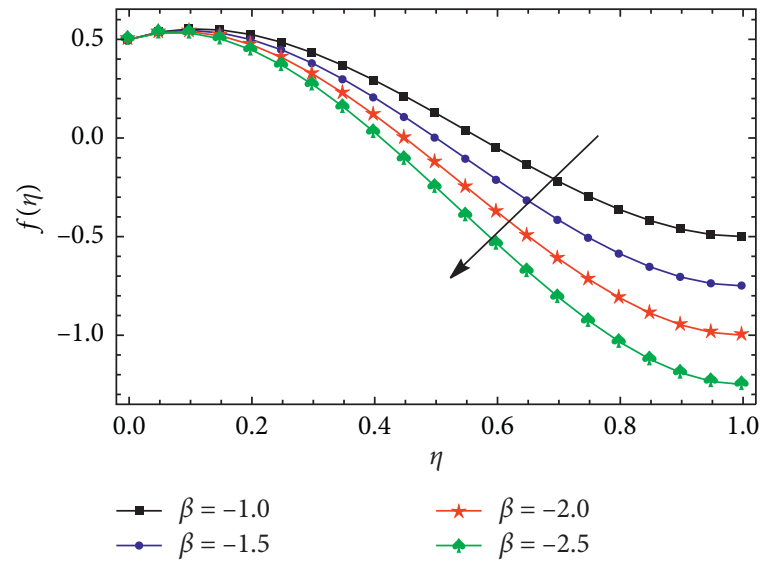

(a)

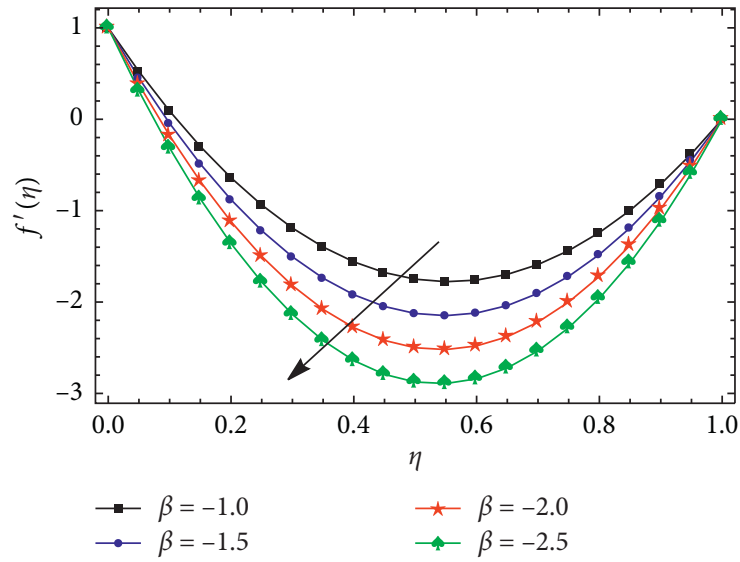

(b)

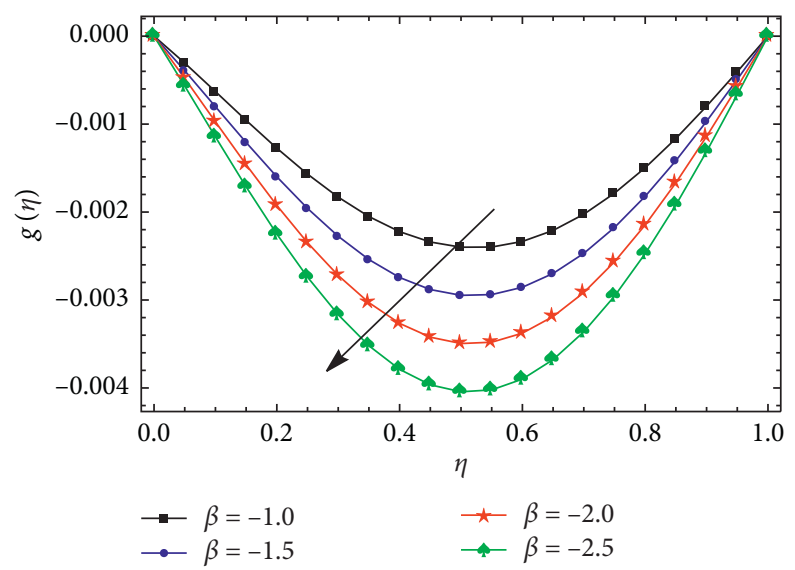

(c)

Figure 7: Effect of negative values of characteristic parameter $\beta$ on the velocity profile when $\phi=0.9, w_{0}=0.5, \Omega=1$, and $M=0.5$. (a) Normal component of velocity. (b) Axial component of velocity. (c) Transverse component of velocity. 

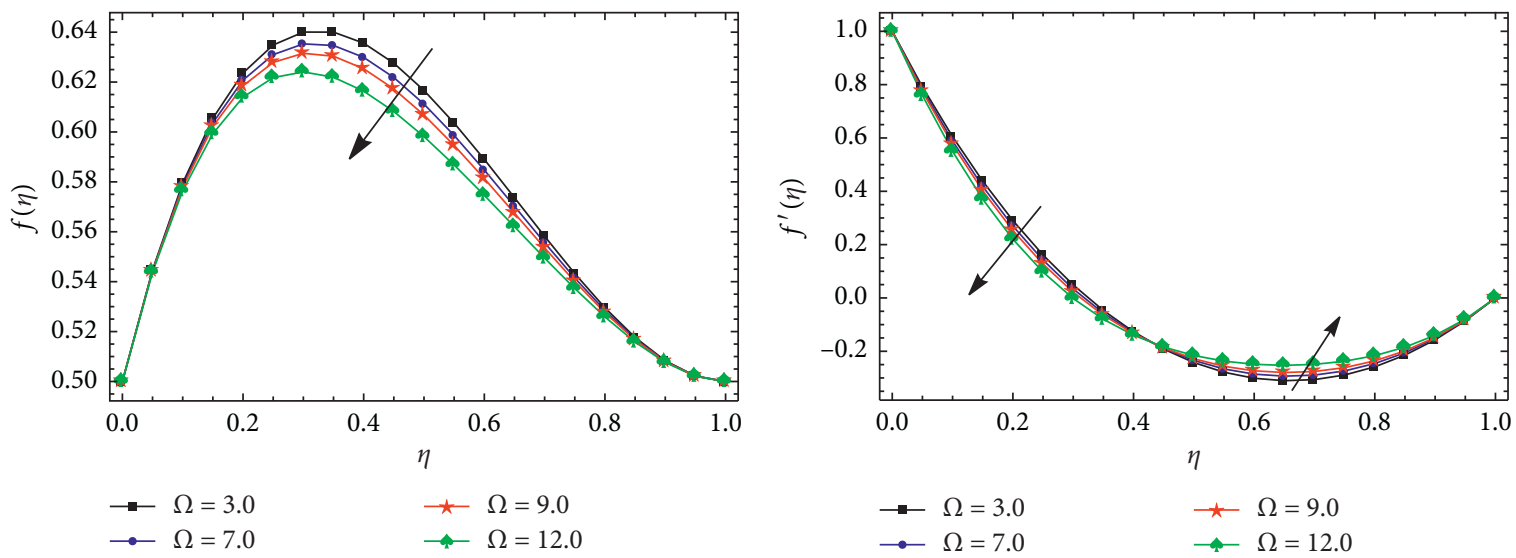

(a)

(b)

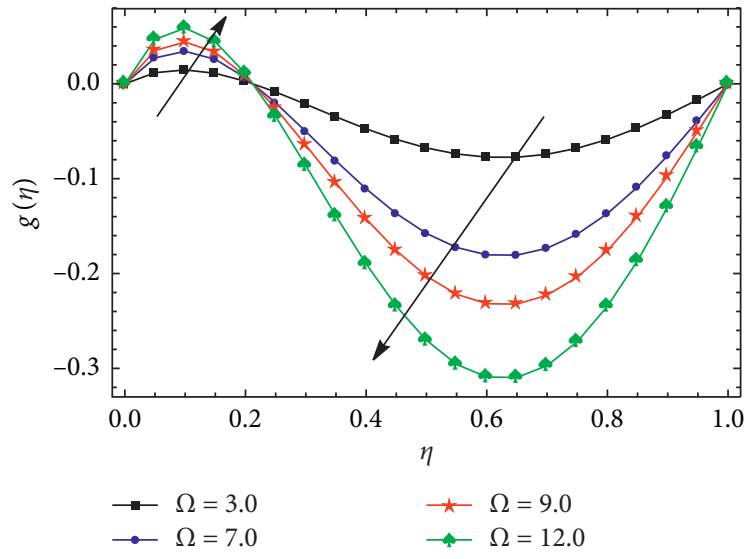

(c)

FiguRE 8: Effect of rotational parameter $\Omega$ on the velocity profile when $\phi=0.2, w_{0}=0.5, \beta=1$, and $M=0.5$. (a) Normal component of velocity. (b) Axial component of velocity. (c) Transverse component of velocity.

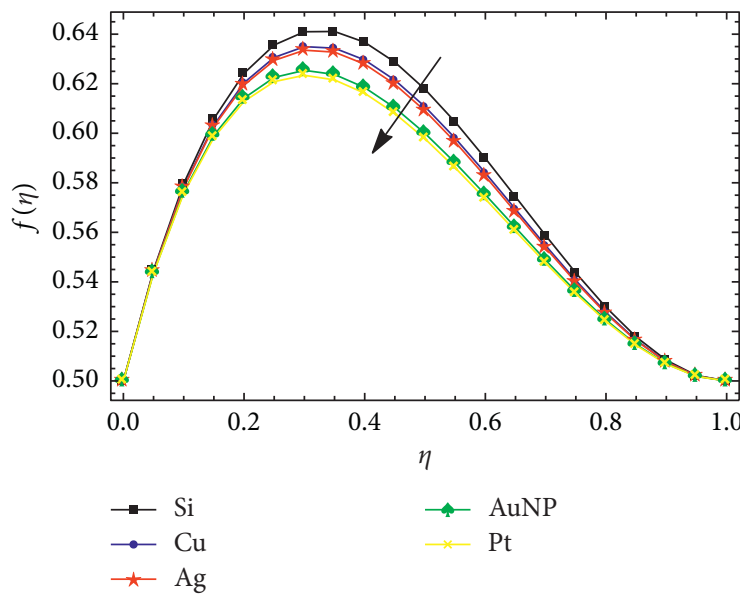

(a)

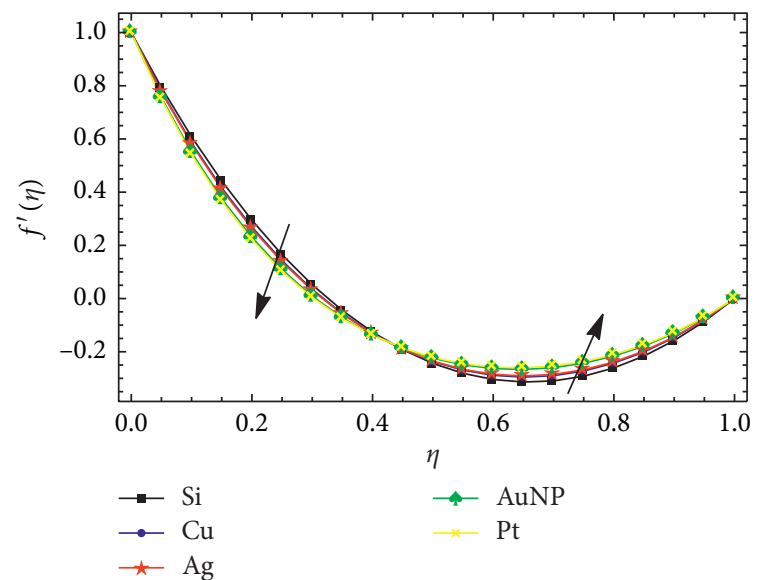

(b)

Figure 9: Continued. 


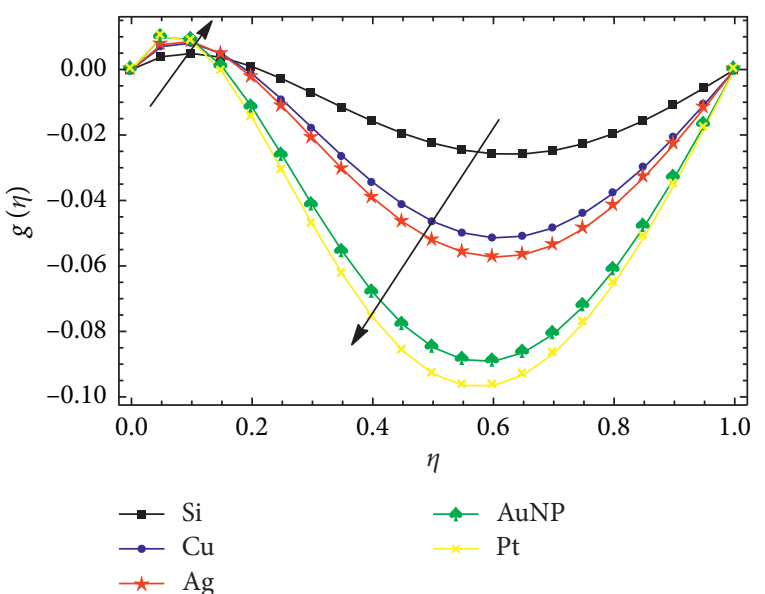

(c)

Figure 9: Effect of various types of nanoparticles on the velocity profile when $\phi=0.2, w_{0}=0.5, \Omega=1, \beta=1$, and $M=0.5$. (a) Normal component of velocity. (b) Axial component of velocity. (c) Transverse component of velocity.

respect to different densities is quite small. In the transverse case, nanofluids with high densities show larger velocity profile in the lower quarter of the channel, whereas a weak reverse and decreasing flow in the remaining of the channel.

\section{Conclusion}

In this article, an unsteady electrically conducting $3 \mathrm{D}$ squeezing flow of nanofluid in a rotating channel on a lower permeable stretching wall is considered. In this study, water is taken as base fluid along with five different types of nanoparticles, including silicon $(\mathrm{Si})$, copper $(\mathrm{Cu})$, silver $(\mathrm{Ag})$, gold $(\mathrm{Au})$, and platinum $(\mathrm{Pt})$, being analyzed in the simulations. Important physical parameters are considered here; the nanoparticle volume fraction $(\phi)$, the suction parameter $\left(w_{0}\right)$, the characteristic parameter of the flow $(\beta)$, the rotation parameter $(\Omega)$, and the magnetic parameter $(M)$. Resulting boundary value system is solved through the HPM and Runge-Kutta-Fehlberg method (RK45). Analysis reveals that the motion of the upper plate significantly effects the velocity profile in the channel. Also, large values of nanoparticle volume fraction reduce the effects of rotation parameter $\Omega$ and magnetic parameter $M$.

\section{Nomenclature}

$\beta$ : $\quad$ Characteristic parameter of the flow

$\Omega$ : $\quad$ Rotation parameter

$M^{2}$ : Magnetic parameter

$w_{0}$ : Suction parameter

$\mathrm{Re}_{x}$ : Local Reynolds number

$\sigma: \quad$ Electrical conductivity

$\rho: \quad$ Density

$\mu$ : $\quad$ Dynamic viscosity

$\eta$ : A scaled boundary-layer coordinate

v: Kinematic viscosity

$\gamma: \quad$ Characteristic constant parameter

$\omega$ : Constant angular velocity

$\phi$ : Nanoparticle volume fraction a: Lower plate stretching rate

$B$ : $\quad$ External uniform magnetic field

$B_{0}$ : Constant magnetic flux density

$C_{f}$ : Skin friction coefficient

$f, g$ : Self-similar velocities

$h(t)$ : Upper plane distance

$J$ : $\quad$ Magnetic flux

$f: \quad$ Fluid phase

$s$ : $\quad$ Solid phase

nf: Nanofluid.

\section{Data Availability}

The authors confirm that the data supporting the findings of this study are available within the article.

\section{Conflicts of Interest}

The authors have no conflicts of interest regarding the publication of this paper.

\section{Acknowledgments}

The authors would like to thank Prince Sultan University for funding this work through the research group Nonlinear Analysis Methods in Applied Mathematics (NAMAM) (group no. RG-DES-2017-01-17).

\section{References}

[1] N. Freidoonimehr, B. Rostami, M. M. Rashidi, and E. Momoniat, "Analytical modelling of three dimensional squeezing nanofluid flow in a rotating channel on a lower stretching porous wall," Mathematical Problems in Engineering, vol. 2014, Article ID 692728, 14 pages, 2014.

[2] K. V. Wong and O. De Leon, "Applications of nanofluids: current and future," Advances in Mechanical Engineering, vol. 2, p. 519659, 2010. 
[3] W. Yu and H. Xie, "A review on nanofluids: preparation, stability mechanisms, and applications," Journal of Nanomaterials, vol. 2012, Article ID 435873, 17 pages, 2012.

[4] S. U. S. Choi and J. A. Eastman, "Enhancing thermal conductivity of fluids with nanoparticles," Technical report, Argonne National Laboratory, Lemont, IL, USA, 1995.

[5] M. E. Meibodi, M. Vafaie-Sefti, A. Rashidi, and M. Tabasi, "An estimation for velocity and temperature profiles of nanofluids in fully developed turbulent flow conditions," International Communications in Heat and Mass Transfer, vol. 37, no. 7, pp. 895-900, 2010.

[6] D. Kalal, "Analogies between the heat and the momentum transfer," in Numerical Modelling and Experimental Testing of Heat Exchangers, pp. 157-171, Springer, Berlin, Germany, 2019.

[7] K. S. Hwang, S. P. Jang, and S. U. S. Choi, "Flow and convective heat transfer characteristics of water-based al2o3 nanofluids in fully developed laminar flow regime," International Journal of Heat and Mass Transfer, vol. 52, no. 1-2, pp. 193-199, 2009.

[8] A. Kanjirakat and R. Sadr, "Near-wall velocity profile measurement for nanofluids," AIP Advances, vol. 6, no. 1, p. $015308,2016$.

[9] A. Alsaedi, M. Awais, and T. Hayat, "Effects of heat generation/absorption on stagnation point flow of nanofluid over a surface with convective boundary conditions," Communications in Nonlinear Science and Numerical Simulation, vol. 17, no. 11, pp. 4210-4223, 2012.

[10] K. Ali, M. Z. Akbar, M. F. Iqbal, and M. Ashraf, "Numerical simulation of heat and mass transfer in unsteady nanofluid between two orthogonally moving porous coaxial disks," AIP Advances, vol. 4, no. 10, p. 107113, 2014.

[11] M. A. Mansour and S. E. Ahmed, "A numerical study on natural convection in porous media-filled an inclined triangular enclosure with heat sources using nanofluid in the presence of heat generation effect," Engineering Science and Technology, an International Journal, vol. 18, no. 3, pp. 485495, 2015.

[12] A. G. Madaki, R. Roslan, M. S. Rusiman, and C. S. K. Raju, "Analytical and numerical solutions of squeezing unsteady cu and tio2-nanofluid flow in the presence of thermal radiation and heat generation/absorption," Alexandria Engineering Journal, vol. 57, no. 2, pp. 1033-1040, 2018.

[13] M. Sheikholeslami and D. D. Ganji, "Heat transfer of cu-water nanofluid flow between parallel plates," Powder Technology, vol. 235, pp. 873-879, 2013.

[14] U. Khan, N. Ahmed, M. Asadullah, and S. Tauseef Mohyuddin, "Effects of viscous dissipation and slip velocity on twodimensional and axisymmetric squeezing flow of $\mathrm{Cu}$-water and Cu-kerosene nanofluids," Propulsion and Power Research, vol. 4, no. 1, pp. 40-49, 2015.

[15] M. Sheikholeslami and D. D. Ganji, "Nanofluid hydrothermal behavior in existence of lorentz forces considering joule heating effect," Journal of Molecular Liquids, vol. 224, pp. 526-537, 2016.

[16] M. Zubair, Z. Shah, A. Dawar, S. Islam, P. Kumam, and A. Khan, "Entropy generation optimization in squeezing magnetohydrodynamics flow of casson nanofluid with viscous dissipation and joule heating effect," Entropy, vol. 21, no. 8, p. 747, 2019.

[17] T. Hayat, T. Muhammad, A. Qayyum, A. Alsaedi, and M. Mustafa, "On squeezing flow of nanofluid in the presence of magnetic field effects," Journal of Molecular Liquids, vol. 213, pp. 179-185, 2016.
[18] A. S. Dogonchi and D. D. Ganji, "Investigation of mhd nanofluid flow and heat transfer in a stretching/shrinking convergent/divergent channel considering thermal radiation," Journal of Molecular Liquids, vol. 220, pp. 592-603, 2016.

[19] O. O. Sharifuddin Ansari, M. Trivedi, and S. P. Goqo, "Magnetohydrodynamic bioconvective casson nanofluid flow: a numerical simulation by paired quasilinearisation," Journal Archive, vol. 6, 2020.

[20] X.-Q. Wang and A. S. Mujumdar, "A review on nanofluidspart I: theoretical and numerical investigations," Brazilian Journal of Chemical Engineering, vol. 25, no. 4, pp. 613-630, 2008.

[21] H. I. Andersson and B. S. Dandapat, "Flow of a powerlaw fluid over a stretching sheet," Appl Anal Continuous Media, vol. 1, no. 339, 1992.

[22] M. Sajid, I. Ahmad, T. Hayat, and M. Ayub, "Unsteady flow and heat transfer of a second grade fluid over a stretching sheet," Communications in Nonlinear Science and Numerical Simulation, vol. 14, no. 1, pp. 96-108, 2009.

[23] E. W. Mrill, A. M. Benis, E. R. Gilliland, T. K. Sherwood, and E. W. Salzman, "Pressure flow relations of human blood hollow fibers at low flow rates," Journal of Applied Physiology, vol. 20, pp. 954-967, 1965.

[24] D. A. McDonald, Blood Flows in Arteries, Arnold, London, UK, 2nd edition, 1974.

[25] M. Sheikholeslami, D. D. Ganji, and H. R. Ashorynejad, "Investigation of squeezing unsteady nanofluid flow using adm," Powder Technology, vol. 239, pp. 259-265, 2013.

[26] A. K. Gupta and S. Saha Ray, "Numerical treatment for investigation of squeezing unsteady nanofluid flow between two parallel plates," Powder Technology, vol. 279, pp. 282-289, 2015.

[27] M. Azimi and R. Riazi, "Analytical solution of unsteady gowater nanofluid flow and heat transfer between two parallel moving plates," Indian Journal of Chemical Technology (IJCT), vol. 23, no. 1, pp. 47-52, 2016.

[28] N. Hedayati and A. Ramiar, "Investigation of two phase unsteady nanofluid flow and heat transfer between moving parallel plates in the presence of the magnetic field using GM," Transport Phenomena in Nano and Micro Scales, vol. 4, no. 2, pp. 47-53, 2016.

[29] M. Sheikholeslami and D. D. Ganji, "Nanofluid flow and heat transfer between parallel plates considering brownian motion using DTM," Computer Methods in Applied Mechanics and Engineering, vol. 283, pp. 651-663, 2015.

[30] M. S. Abdel-Wahed, E. M. A. Elbashbeshy, and T. G. Emam, "Flow and heat transfer over a moving surface with non-linear velocity and variable thickness in a nanofluids in the presence of brownian motion," Applied Mathematics and Computation, vol. 254, pp. 49-62, 2015.

[31] A. S. Dogonchi and D. D. Ganji, "Thermal radiation effect on the nano-fluid buoyancy flow and heat transfer over a stretching sheet considering Brownian motion," Journal of Molecular Liquids, vol. 223, pp. 521-527, 2016.

[32] M. Mustafa and J. A. Khan, "Model for flow of casson nanofluid past a non-linearly stretching sheet considering magnetic field effects," AIP Advances, vol. 5, no. 7, p. 077148, 2015.

[33] N. G. Rudraswamy, B. J. Gireesha, and M. R. Krishnamurthy, "Effect of internal heat generation/absorption and viscous dissipation on MHD flow and heat transfer of nanofluid with particle suspension over a stretching surface," Journal of Nanofluids, vol. 5, no. 6, pp. 1000-1010, 2016. 
[34] S. M. R. Shah Naqvi, T. Muhammad, and M. Asma, "Hydromagnetic flow of casson nanofluid over a porous stretching cylinder with Newtonian heat and mass conditions," Physica A: Statistical Mechanics and its Applications, vol. 550, p. 123988, 2020.

[35] R. Kandasamy, I. Muhaimin, A. B. Khamis, and R. b. Roslan, "Unsteady hiemenz flow of cu-nanofluid over a porous wedge in the presence of thermal stratification due to solar energy radiation: lie group transformation," International Journal of Thermal Sciences, vol. 65, pp. 196-205, 2013.

[36] B. Bin-Mohsin, N. Ahmed, U. Khan et al., "A bioconvection model for a squeezing flow of nanofluid between parallel plates in the presence of gyrotactic microorganisms," The European Physical Journal Plus, vol. 132, no. 4, p. 187, 2017.

[37] A. Dib, A. Haiahem, and B. Bou-Said, "Approximate analytical solution of squeezing unsteady nanofluid flow," Powder Technology, vol. 269, pp. 193-199, 2015.

[38] R. Naz, Z. Shah, P. Kumam, P. Thounthong, and M. Sohail, "Exploration of temperature dependent thermophysical characteristics of yield exhibiting non-Newtonian fluid flow under gyrotactic microorganisms," AIP Advances, vol. 9, no. 12, 2019.

[39] N. Ahmed, S. T. Mohyud-Din, Adnan, and U. Khan, "Thermo-diffusion and diffusion-thermo effects on flow of second grade fluid between two inclined plane walls," Journal of Molecular Liquids, vol. 224, pp. 1074-1082, 2016.

[40] U. Khan, S. T. Mohyud-Din, Adnan, and M. Asadullah, "Analytical and numerical investigation of thermal radiation effects on flow of viscous incompressible fluid with stretchable convergent/divergent channels," Journal of Molecular Liquids, vol. 224, pp. 768-775, 2016.

[41] U. Khan, S. T. Mohyud-Din, K. S. Nisar, Adnan, and S. Z. Zaidi, "Investigation of thermal transport in multishaped cu nanomaterial-based nanofluids," Materials, vol. 13, no. 12 , p. 2737, 2020.

[42] U. Khan, N. Ahmed, S. T. Mohyud-Din et al., "Impacts of freezing temperature based thermal conductivity on the heat transfer gradient in nanofluids: applications for a curved riga surface," Molecules, vol. 25, no. 9, p. 2152, 2020.

[43] R. Naz, S. I. Abdelsalam, and M. Sohail, "On the onset of entropy generation for a nanofluid with thermal radiation and gyrotactic microorganisms through $3 \mathrm{~d}$ flows," Physica Scripta, vol. 95 , no. 4 , p. $045206,2020$.

[44] M. Sheikholeslami and D. D. Ganji, "Numerical investigation for two phase modeling of nanofluid in a rotating system with permeable sheet," Journal of Molecular Liquids, vol. 194, pp. 13-19, 2014.

[45] M. Sheikholeslami and H. B. Rokni, "Nanofluid two phase model analysis in existence of induced magnetic field," International Journal of Heat and Mass Transfer, vol. 107, pp. 288-299, 2017.

[46] J. H. He, "Homotopy perturbation technique," Computer Methods in Applied Mechanics and Engineering, vol. 178, no. 3-4, pp. 257-262, 1999.

[47] J.-H. He, "A coupling method of a homotopy technique and a perturbation technique for non-linear problems," International Journal of Non-linear Mechanics, vol. 35, no. 1, pp. 37-43, 2000.

[48] J.-H. He, "Homotopy perturbation method: a new nonlinear analytical technique," Applied Mathematics and Computation, vol. 135, no. 1, pp. 73-79, 2003.

[49] J.-H. He, "Homotopy perturbation method for solving boundary value problems," Physics Letters A, vol. 350, no. 1-2, pp. 87-88, 2006.
[50] A. M. Siddiqui, M. Ahmed, and Q. K. Ghori, "Couette and Poiseuille flows for non-Newtonian fluids," International Journal of Nonlinear Sciences and Numerical Simulation, vol. 7, no. 1, pp. 15-26, 2006.

[51] A. M. Siddiqui, R. Mahmood, and Q. K. Ghori, "Thin film flow of a third grade fluid on a moving belt by he's homotopy perturbation method," International Journal of Nonlinear Sciences and Numerical Simulation, vol. 7, no. 1, pp. 7-14, 2006.

[52] N. Herisanu and V. Marinca, "Optimal homotopy perturbation method for non conservative dynamical system of a rotating electrical machine," Zeitschrift für Naturforschung A, vol. $67,2012$.

[53] F. Wang and W. L. Zhang, "A new extended homotopy perturbation method for nonlinear differential equations," Mathematical and Computer Modelling, vol. 55, 2012.

[54] A. N. Golshan, S. S. Nourazar, H. G. Fard, A. Yaldirim, and A. Campo, "A modified homotopy perturbation method coupled with the fourier transform for nonlinear and singular lane-emden equations," Applied Mathematics Letters, vol. 26, 2013.

[55] M. Qayyum, H. Khan, M. T. Rahim, and I. Ullah, "Modeling and analysis of unsteady axisymmetric squeezing fluid flow through porous medium channel with slip boundary," PLoS One, vol. 10, no. 3, 2015.

[56] M. Qayyum and H. Khan, "Behavioral study of unsteady squeezing flow through porous medium," Journal of Porous Media, vol. 19, no. 1, pp. 83-94, 2016.

[57] S. S. Nourazar, M. Habibi Matin, and M. Simiari, "The HPM applied to MHD nanofluid flow over a horizontal stretching plate," Journal of Applied Mathematics, vol. 2011, Article ID 876437, 17 pages, 2011.

[58] M. Hatami, D. Jing, D. Song, M. Sheikholeslami, and D. D. Ganji, "Heat transfer and flow analysis of nanofluid flow between parallel plates in presence of variable magnetic field using hpm," Journal of Magnetism and Magnetic Materials, vol. 396, pp. 275-282, 2015.

[59] A. Malvandi, D. D. Ganji, F. Hedayati, and E. Yousefi Rad, "An analytical study on entropy generation of nanofluids over a flat plate," Alexandria Engineering Journal, vol. 52, no. 4, pp. 595-604, 2013.

[60] N. Dalir and S. S. Nourazar, "Solution of the boundary layer flow of various nanofluids over a moving semi-infinite plate using HPM," Mechanics, vol. 20, no. 1, pp. 57-63, 2014.

[61] M. Mustafa, T. Hayat, and S. Obaidat, "On heat and mass transfer in the unsteady squeezing flow between parallel plates," Meccanica, vol. 47, no. 7, pp. 1581-1589, 2012.

[62] M. Qayyum, H. Khan, M. T. Rahim, and I. Ullah, "Analysis of unsteady axisymmetric squeezing fluid flow with slip and noslip boundaries using OHAM," Mathematical Problems in Engineering, vol. 2015, Article ID 860857, 11 pages, 2015. 